\title{
Brainwave authentication using emotional patterns
}

\section{Violeta Tulceanu}

Gh. Zane Institute, Romanian Academy, Iasi Branch, Romania

and

Faculty of Computer Science, Al.I. Cuza, University of Iasi, Romania Email: violeta.tulceanu@infoiasi.ro

\begin{abstract}
In this paper, we are proposing a new concept of authentication that uses credentials to collect and analyse meta-information about the users' mental and emotional state. Identification is performed by verifying the cerebral activation pattern as a result of emotional stimulation using abstract concepts as auditive stimuli. Authorisation is granted if the user's state of mind allows him to responsibly use the resources he is entitled to. The data collected is further used to make predictions about the future behaviour of the user, by analysing the slow variations of the data over time. This type of authentication has applications in fields such as the military, e-learning, health, etc., where it is necessary to be able to establish whether the user was acting responsibly and of his own accord.
\end{abstract}

Keywords: authentication; brainwaves; EEG; biometrics; signal processing; emotions; emotional patterns; pattern extraction; feature extraction.

Reference to this paper should be made as follows: Tulceanu, V. (xxxx) 'Brainwave authentication using emotional patterns', Int. J. Advanced Intelligence Paradigms, Vol. X, No. Y, pp.xxx-xxx.

Biographical notes: Violeta Tulceanu is a $\mathrm{PhD}$ student at the Faculty of Computer Science at the 'Al.I. Cuza in Iasi, with an interest in biometric authentication, brain-computer interfacing and neuroscience. She is specialised in information security (biometrics, computer vision and heterogeneous sensor networks). Also, she has experience in teaching code theory and cryptography and algebraic foundations of computer science.

This paper is a revised and expanded version of a paper entitled 'Comprehensive brainwave authentication using emotional stimuli' presented at 20th European Signal Processing Conference (EUSIPCO 2012), Bucharest, Romania, 27-31 August 2012.

\section{Introduction}

All action is powered by emotion. The true engine of motivation is our capacity to perceive pleasure and fear pain, and thus, reward and punishment. Our ability to react to dangerous situations is directly related to our capacity to relate to our environment, and willingness to self-preserve.

Copyright @ 20XX Inderscience Enterprises Ltd. 
People in well-balanced emotional states will react according to factors such as context, group expectations, education, cultural background, social norms and personal inclinations within what is referred to as acceptable within these norms. Namely, will behave as what game theory calls rational players.

However, human beings are not static entities, and as context, knowledge and perceived universe evolve, their emotional patters will undergo modifications. This results in a rearrangement of priorities, as shifts in the relevance of different types of stimuli attach new values to the emotional reward obtained by reacting in a given manner.

In other words, there is either an addition of variables in the game where they are rational players, or there is a complete overturn of their previous logic and reasoning mechanism, leading to very different actions being taken in the same absolute context.

To be more precise, as a human evolves, there may occur internal or external disruptions that lead to the change of emotional reaction patterns. As human perception is subjective, a shift of emotional responses will result in a different semantic interpretation of the visible universe and different assumptions over the invisible universe. Also, the definitions of value may change, and what is perceived as gain will be revised. Reasoning rules are likely to e altered, as well as the relevance of social norms and the importance of group perception and group gain.

Thus, altered emotional responses result in new action patterns, that might defy previously expected responses, norms and rational gain.

Concretely, these triggers may be either dramatic emotional trauma, burnout, depression, stress, paralysing fear, lack of self worth, and a distorted perception of reality because of isolation, manipulation or abuse.

An altered emotional state can make a person that would normally take charge in a given situation shy away from responsibility, perceiving even the most menial of tasks as overwhelming. A mind (and here we refer to the classic Oxonian definition of the mind) stressed beyond the supportability threshold will go into self-preservation mode, choosing to ignore stimulation and even defy self-preservation. A desolate resignation and lack of interest in all pleasure can accompany burnout and depression. Manic, erratic, absurd outbursts of pure wrath, dramatic emotional discharges can override rational gain and socially acceptable behaviour. Paranoid guilt and lack of self confidence block all constructive solutions to crises or to what is perceived as crisis.

War veterans, victims of abuse, people with mood disorders and those exposed to prolonged stress in high-responsibility positions are among those prone to the above-mentioned.

Starting with the assumption that human emotions are quantifiable and form activation patterns over the cortex, that can be expressed via an algebraic model, we propose an authentication scheme that can capture altered emotional responses early on, and decide whether the user can responsibly act when granted access to the resources.

The scheme is challenge-response type, where the challenge is represented by listening to a series of words that the user personally finds to hold an emotional charge. The words can be either abstract or concrete nouns, but should be closely related to a personal memory that elicits an emotional response.

Thus, in this authentication scheme, we are interested with the following: firstly, that it should be able to establish the identity of the user and to offer information about whether the user entitled to access the resources is indeed in front of the computer, and not someone who obtained his credentials by other means. Secondly, it should offer 
information about what the user's current state of mind is, and whether he can responsibly handle the resources he is entitled to access. Thirdly, it should be able to detect if the user is acting of his free accord or not. Also, it should be able to provide a prediction about how the user will act in the future. And finally, it should be able to adapt over time.

In order to asses the feasibility and performance of our proposal, we will try to answer the following issues:

a whether emotional responses can act as credentials

b whether it is possible to trigger emotional responses using only the semantic of auditive stimuli

c which would be the suitable representations of the emotional responses

d how can we make the scheme capable of distinguishing and classifying a new emotional response

e which is the accuracy with which we can distinguish between individuals using this scheme

f how can we make the scheme capable of predicting potentially irresponsible/dangerous behaviour.

\section{Discussion on the suitability of using emotional responses as credentials}

For a long time, emotions have stood in a cone of shadow in the scientific world, since they could not be clearly described by anatomical, physiological or biochemical analysis. They have been cast out along with other ineffable 'life forces' that escaped the rationalism dominating medicine since the 19th century.

However, modern research techniques are bringing back emotion as a scientifically observable entity, and show that far from being ineffable, emotion is completely neurological, and lies at the core of all learning mechanisms.

Firstly, we should differentiate between raw, primary affect and feelings. Affect does not involve higher cognitive functions, and is related to basic survival strategies that allow the species to avoid extinction. Feelings, on the other hand, are influenced by social and cultural factors, and involve conscious processing, thus placing themselves on top of the instinctive level of raw affect.

In Panksepp (2008), the creator of 'affective neuroscience', identifies seven affective systems, that are analogue throughout several mammalian species. By localised electrical stimulations of specific neural systems (LESSNS) and chemical stimulation of these systems, he is capable of eliciting emotional responses, proving that emotions are thoroughly neural circuits. These circuits are deep subcortical networks, and will not be perturbed by the partial or total removal of the cortex. Relatively more research has been performed on understanding the anatomical mechanisms underlying human sadness and fear.

Even though the limbic system (hypothalamus, anterior thalamus, cingulate gyrus, hippocampus, amygdala, septal nuclei, orbito-frontal cortex, parts of basal ganglia) has long been accepted as the anatomical system behind emotion, there is work (Meye and 
Kotter, 1992; Brodal, 1982) proving that it is impossible to define the exact structures and pathways it includes.

Phelps and Ledoux (2008) identify the ammygdala and the hippocampus as the most important centres involved in controlling emotional responses. Damage to the hippocampus, while the amygdala is still intact will allow the fear CR to manifest, though verbal expression is impended. When the opposite occurs, fear is still reported, but the CR will not appear. They consider that the 'retention of an abstract, cognitive representation of fear may depend on the hippocampus' and the left amygdala.

Phelps and Ledoux (2008) differentiates between conditioned and instructed fear. Thus, a fear response will be triggered when the subject is directly exposed to a stimulus, which is the conditioned fear response. However, Phelps and Olsson (2007) and Poehlmann et al. (2008) notice that there is an equally strong activation of the bilateral amygdala when the subject observes a member of the same species being exposed to fear and knows that there is some likelihood that he may also be exposed to the same stimulus.

Thus, in the apparition of instructed fear, the following are involved: a symbolic communication system (language) for acquisition, the hippocampal memory system that underlies the retention of the abstract representation and the amygdala that mediates the physiological expression.

The above mean that instructed fear is taught by warning, and that fears that are imagined and anticipated, albeit never experienced, will produce the same type of brain activity that real exposure to the stimuli would.

This brings up the issue of contextualisation. Anticipation was mentioned as a trigger for instructed fear. Phelps and Ledoux (2008) gives exemplifies with the difference between seeing a bear at a zoo and seeing a bear in a forest. In the first case, no fear response will appear, as there is no anticipation of an attack. In the second case, anticipation is present, and the response will appear.

Thus, imagination and anticipation can trigger a fear response. However, the appropriate context is necessary for anticipation to occur. This leads us to question whether it is possible to have a fear response based on imagination alone, without the need for any particular context.

Phelps and Ledoux (2008) mentions that periods of intense stress potentiate the brain's ability to form unconscious emotional memories in the detriment of conscious memories.

In consequence, we consider that a potential substitute for anticipation when trying to trigger an emotion could be memory. Rememorating a strong emotion and the context where it occurred should trigger an emotional response [as also stated by Friesen et al. (1983), who corroborated this with other measures as well; Salt et al. (1976), for instance, asked participants to imagine positive or negative events in their lives, and then performed EMG; patterns similar to those obtained with emotional imagery and films have also been obtained with emotional pictures (Losch et al., 1986; Bradley et al., 1993; Cacioppo et al., 2003) and sounds (Lang and Bradley, 2000; Cacioppo et al., 2003)]. The amplitude of this response will depend on the user's current state of mind. Simple rememoration of an unpleasant event is expected to trigger a low emotional response if the subject is in a normal state of mind. However, if the mental state is not stable, then the emotional response should be augmented. 
There is still an issue pending - that of measuring brain activity in the subcortical areas. The abovementioned work was carried out either using invasive techniques, or fMRI, neither of which are applicable in the case of brainwave authentication.

As we intend to use EEG, we will be measuring brain activity at scalp level. Subcortical activity cannot be measured by EEG, which means that we cannot directly assess the activity in the amygdala, hippocampus, thalamus, etc. Instead, we can assess the activity in the cortical projections of the amygdala. Such areas would be the dorsolateral prefrontal cortex and the median prefrontal cortex (Phelps and Ledoux, 2008).

Up to now, we have discussed how emotions arise, and what is the neurological mechanism behind them. We have proved that they are physiologically determined and thoroughly measurable. Furthermore, they do not depend on the presence of direct stimulation, but can be acquired and triggered by means of language. Finally, we mentioned the correlation between memory and emotional responses.

However, the emotions we have discussed so far are not feelings. The latter are conscious and conditioned by social and cultural factors, thus requiring cortical activity.

Phelps and Ledoux (2008) states that emotional feelings arise when the working memory is occupied by the fact that an emotional system of the brain is active. The difference between states of consciousness arises from the fact that the memory is occupied either by emotional or non-emotional events, and not from the mechanism underlying emotion.

Friesen et al. (1983) claim it is possible to find patterns for emotions by simultaneous examination of a number of indices of autonomic nervous system activity. Friesen et al. (1983) provided evidence for emotion-specific autonomic patterns. The measures they used included heart rate, skin conductance, finger temperature, etc.

The patterns in Friesen et al. (1983) are given by means of decision trees, where each node is a bodily measurement. However, these bodily measurements have been proved to covary with activity in different areas of the cortex (ex., Featherstone et al., 2004; Nagai et al., 2005). This should be due to the fact that the subcortical areas responsible for emotions have projections at the cortical level, and the neurotransmitters they produce when a certain stimulus appears will reach the cortex via the different emergent pathways from that area.

In consequence, we consider that it would be correct to relabel the decision trees so that instead of peripheral measurements such as skin conductance and heart rate, we should have features extracted from recorded brain activity that covaries with the above measurements.

This is confirmed by recent work performed by Just et al. (2010), where it is proved that concrete nouns have a semantic representation at a neurological level, and that concrete countable nouns can be represented using underlying brain codes. In other words, each word will be uniquely represented by the activation of a particular combination of cortical networks, each associated with a semantic dimension of the given word. Furthermore, the activated networks overlap those activated by performing the actions denoted by the semantics associated with the word. We consider this an important discovery, as it proves that imagination of a context will activate the same brain areas as being in the given context, which comes to support what we have been attempting to prove theoretically in Section 2 with respect to emotions, namely that that they can be 
triggered via imagination and memory using only words and have unique cortical representations.

We know that emotions have a neurological representation as subcortical systems, which in turn have projections at the cortical level. Also, we know that emotions can be learned and triggered given the existence of a communication channel (language) by imagination and anticipation. However, we deduce from previous work that memory could replace anticipation in stimulating an emotional response. Thus, we consider that hearing and focusing on an emotionally charged word activates firstly, by the semantic associated to it, the networks involved in its neurological representation, but also the memory, which in turn will lead to a cascading activation of the cortical networks (bringing up context, associations, timing) finally leading to those that represent the given emotion.

The response to an authentication challenge should be the combination of the codes of the networks activated, which is highly personal to each user, given the fact that words with emotional charge will evoke very different associations from one user to another, and that the associations themselves will have their own encodings.

With the above, we have established the unique and measurable character of emotional responses, as well as the fact that it is possible to use words as stimuli. In consequence, we deduce that it is acceptable to use neurosemantic representations of emotional responses as credentials.

\section{Proposed authentication scheme}

In our first attempt towards emotion-based brainwave authentication we had proposed the scheme we described in Tulceanu (2012). Taking into account the results we obtained on the preliminary set of five subjects, which we detail in the results section, we came to the following authentication scheme:

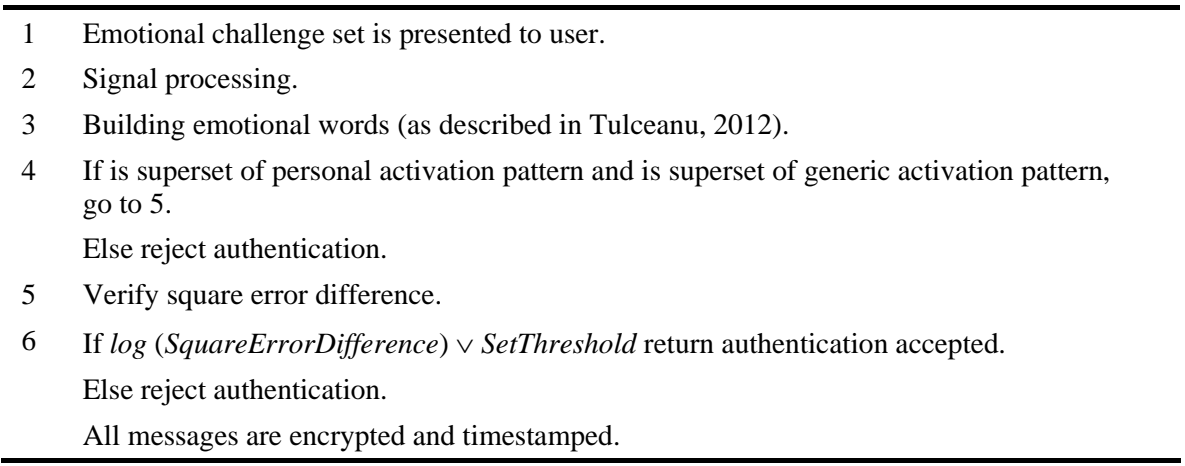

\section{Data acquisition}

We have performed two sets of tests, on 5, respectively 24 subjects. The purpose of the first set was to verify whether we could extract a preliminary set of emotional patterns and whether these make it possible to distinguish between subjects. The second set was 
meant to provide more accuracy and a sufficiently ample group in order to assess authentication. Both sets of tests were performed via full EEG using the 10/20 international electrode system in hospital conditions.

For the first group we have experimented with using three types of mental tasks, in order to evaluate which would be more suitable for authentication purposes. Recording of reference brain signal, eyes closed without stimulation was performed between different types of tasks, for 15 seconds.

The first type involved auditive stimulation. Thus, we selected a list of emotions that would act as challenges: contempt, disgust, fear, worry, pleasure, affection, love, pride, hope and sadness. Each subject was asked to create a list of three words he associated with each emotion, which produced a 30-word long list. Each word was to be focused on for five seconds while reminiscing circumstances associated with the given word.

The second type of task required setting three personalised images they would associate with four words that they related to the images and four that were void of meaning in the given context. They were meant to focus on each word for five seconds.

The final task was to set a mental password, which they were meant to later recompose from letters highlighted on alphabet screens. Once the password was completed, the subjects could halt the experiment.

The first group subjects went through two data acquisition sessions, with one or two days in-between.

For the second group, we have renounced the visual task and the password task, since the first type of stimulation better suits our further purposes, namely being able to model neurological representations of abstract concepts and express their semantic irrespective of the signal per se.

The group consisted of 24 healthy persons of both genders, aged 20-60, that were part of the staff (both medical and auxiliary) of the Brasov Hospital of Psychiatry and Neurology, where the tests were conducted.

The electrode placement was the same as for the preliminary tests, following the International 10/20 system. The difference, however, was that the reference electrode was Pz. Thus, the following 16 channels were taken into account: Fp1Pz (ch1), F3Pz (ch2), C3Pz (ch3), P3Pz (ch4), O1Pz (ch5), F7Pz (ch6), T3Pz (ch7), T5Pz (ch8), Fp2Pz (ch9), F4Pz (ch10), C4Pz (ch11), P4Pz (ch12), O2Pz (ch13), F8Pz (ch14), T4Pz (ch15), T6Pz (ch16). They were positioned as in Figure 1. Because $\mathrm{Pz}$ is used as reference a channel is shortcutted and the results are taken over by another channel.

Our preliminary tests showed that the test sessions should be short, as to avoid signal non-stationary sources such as fatigue. Also, repeating a word in the same session meant introducing an anticipation factor that although not overwhelmingly significant, we would rather avoid.

In consequence, each subject underwent three test sessions, each 180 seconds long, listening to a list of 33 words they had selected, three per emotion, without repeating the words in the same session. The subjects were asked to keep their eyes closed and their hands on the armrests, and there were no sources of external noise. The first 15 seconds were recorded without stimulation in order to allow the subjects to relax, after which they were given a sound cue that the word list would begin. They were then required to focus on each word for five seconds. We rejected the third recording from the first subject because the subject moved during the session. This leads to a total number of 71 recordings. 
Figure 1 Electrode placement (see online version for colours)

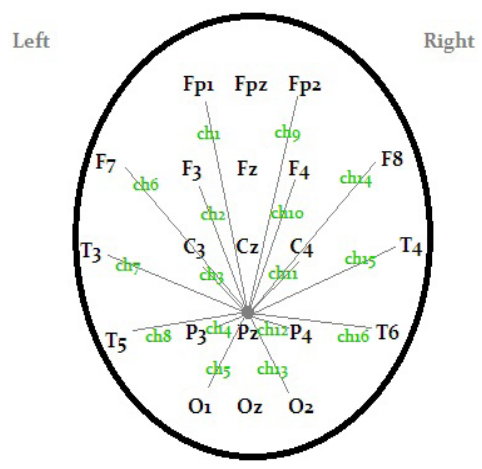

\subsection{Signal processing}

The sampling frequency was $300 \mathrm{~Hz}$, and a B-form smoothing spline (tolerance 1) was applied in order to eliminate noise induced by the powerline, eye movements, muscular movements and the cardiac rhythm. A scaling of 0.01 was further applied. Lost signal was handled by using the fragment before and after the gap for interpolation using a left-sided and right-sided autoregressive model and then cross-fading to obtain the lost values.

As fatigue, blinking, alternation of visual and auditive stimuli, switching between alpha and gamma brain activity give the signal a non-stationary character, each sample was split into one second frames, which were further split into 1662.5 mseconds long subframes, using a 50 msecond overlap.

The power spectral density (PSD) was calculated for each subframe via the Welch averaged modified periodogram approach.

We further set 12 centroids, one corresponding to each of the ten emotions, and one for the indifferent state and alpha rhythm. Each subfragment was marked as to allow the translation to the initial signal. As we used the software we had already developed, the signal processing method is the same as the one described in Tulceanu (2012).

\section{Emotional patterns: building the user models}

After studying the data and modelling it as we described in Tulceanu (2012) (using words over the alphabet of centroid labels and a bijective translation function from labels set to PSD features and finally to original signal), we are encouraged to make the following statements about the entire dataset:

1 It is possible to distinguish accurately between persons using the neural representation of their emotions.

2 Emotions can be encoded as ‘emotional words' (defined over an alphabet where symbols are the labels of the class representatives of the classes with dominant frequencies in the vectors of inverted frequency indexes that were calculated for the extracted classes of features). 
3 'Emotional words' induce a language that can be modelled by an automaton (Turing machine, Petri net, etc., we calculated vectors of inverted frequency indexes for the classes of features that were extracted, and the class representative labels are the symbols in the alphabet over which the words are defined).

4 Different emotions induce unique activation patterns in the brain: each emotion is distinguishable over a set of channels particular to each user, on each determining an 'emotional word'.

5 The activation patterns can be regarded as configurations of an (memory and timed) automaton (or Petri net since it has to have the word in the node or perhaps a composition of automata - one for the language, and one for the brain).

6 The composition of the brain automaton and the emotional language automaton results in the emotional brain automaton.

7 Alterations of the subject's mental state, caused by either illness or the intake of different psychoactive substances will be reflected as 'bad configurations' of the automaton (and thus authorisation denied).

8 The automaton should be able to adapt to slow, slight variations in the user model (words + configurations = channel combinations per emotion) and retain them by creating alternative branches that are timed, and that can replace the old branches when they are frequented more often than those, marking the old branches with the time when they stopped being the main branches. Thus, each branch (configuration, word translation to centroids) should have a counter that says how often it was taken by the subject, and if it becomes his current emotional response (this means we leave some room for variation - the user responses may slightly vary from session to session). Branches have a ranking and an age.

9 The automaton (system) should be able to predict future altered mental states by matching the current run of the subject with the prefix of previous runs of other subjects that terminated in 'bad states' (or study the dynamic of the branches - employ data mining for the dynamic of the branches in order to capture deductions such as 'configuration A evolved to configuration $\mathrm{B}$, and $\mathrm{B}$ evolved to $\mathrm{C}$, and $\mathrm{C}$ to $\mathrm{D}$, so it is likely that configuration A might evolve to D in the future').

To the remarks we make in Tulceanu (2012) which hold for the current dataset, we add the following new remarks:

Remark 1: Let the list of distinguishable emotions over all the channels for a given user, on a certain recording session be established. We define the distinguishability frequency as the number of apparitions of an emotion as distinguishable throughout all channels. The emotions with the highest distinguishability frequency are indicative of the current emotional state of the user.

Remark 2: We consider an emotion stable if it has little variation in distinguishability frequency over different recording sessions.

Remark 3: We consider a channel stable in the representation of an emotion if the given emotion is distinguishable over that channel in over $50 \%$ of the subjects. 
Definition 1: We define an emotional activation pattern as union the channels that present stability in the sense of Remark 3. We have produced 11 such patterns, which we present in.

However, we notice that when analysing the rest of the users, some of the channels were not stable, and the activation pattern of fear contains only channels $5,7,14,15,19$ (for user u3.2 in our dataset).

In order to make the model more easy to use, we have represented the data as 3D and 4D matrices as follows - the words extracted for each emotion on each channels, whether distinguishable or not, are represented as matr (channel, emotion, :), an entry in a 3D matrix.

As each word can be translated in terms of centroids, these are represented as a 4D matrix, where an entry is of the form matr (channel, emotion, centroid_label, centroid_value). Thus, matr (channel, emotion) produces the translation of a word in terms of centroids. The centroids that do not appear in the representation of a word are shown as arrays of 0 .

\section{Results}

\subsection{Distinguishability and stability of emotions}

As we mentioned in Section 2, experiencing a feeling refers to the activation of a series of subcortical emotional systems, which project to the cortex. In consequence, the channels that overlap these projections should present increased neural activity (waves that represent the evoked potential), whereas channels in areas not related to the given emotion will capture only background neural activity.

In other words, if an emotion is distinguishable on a channel in the sense of Tulceanu (2012), then that given brain area was activated by the emotional stimulus. In Table 1 we present the emotions that were distinguishable over the different channels for our first set of subjects. Also, we present the representation of each emotion in terms of centroids. Since channel $\mathrm{O} 1 \mathrm{O} 2$ is primarily linked to the visual cortex, we will leave it out of the analysis. We remind that the emotions were the following:

$\begin{array}{ll}1 & \text { contempt } \\ 2 & \text { disgust } \\ 3 & \text { fear } \\ 4 & \text { worry } \\ 5 & \text { pleasure } \\ 6 & \text { affection } \\ 7 & \text { love } \\ 8 & \text { pride } \\ 9 & \text { hope } \\ 10 & \text { sadness } \\ 11 & \text { indifference. }\end{array}$


Brainwave authentication using emotional patterns

Table 1 Distinguishable emotions on channels

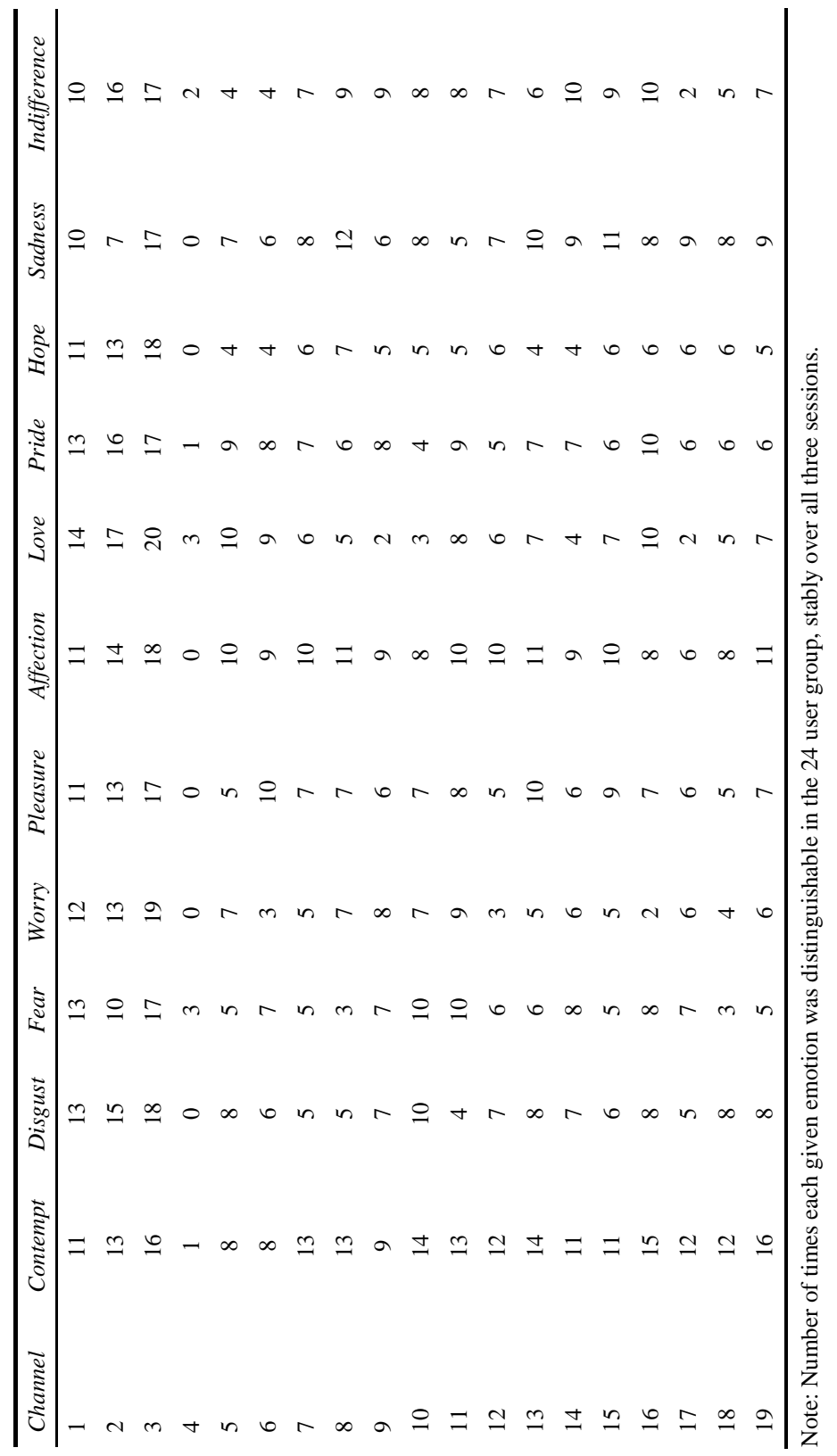


We consider an emotion to be distinguishable and stable over a channel if it was distinguishable in more than half the cases, thus, above, for over 12 subjects. We remind that in Tulceanu (2012) we defined two emotions as being distinguishable if they differ by one or more pairs of centroids (the labels of which translate to PSD). In Figure 2, we show the overall frequency with which different emotions could be distinguished, for the data from all the users in the first group. We notice that for the overall data, actively negative emotions (contempt and worry) are more distinguishable than passive and positive ones (pleasure). The same seems to hold for each user taken separately - passive positive emotions do not stand out much from background EEG activity. However, compared to the general case, we notice that each user will have a higher distinguishability frequency for the emotion that currently describes his state of mind. This was expected, since being distinguishable means standing out against background EEG activity, or, in other words, it denotes an obvious cortical reaction to a given type of emotional stimulus. When the subject is in a given emotional state and hears a word semantically linked to his current mood, memory and imagination are likely to be activated and the corresponding cortical response elicited. If the word is unrelated to the subject's state, then the evoked potential will stand out less against the background EEG activity. This proves 5 from Section 5 .

For instance, for subject bc, contempt and disgust were the most distinguishable emotions, indicating that this was the current disposition of the subject. Pride was much below the average distinguishability frequency (overall data). Love was distinguishable four times in both sessions, so this would make it a stable emotion (in the sense of Remark 4), along with disgust (frequencies 7, respectively 8) and hope (4, respectively $5)$. Affection had a great variation. For subject td, the most stable emotions were worry (fq.8;10) contempt (fq.5;8)and disgust (fq.6;4). During the first session, the subject had high responsiveness to positive emotions (love, pride and hope), whereas during the second session this was not present any more. Finally, for subject vg, we observe that contempt, disgust and fear are not stable, and the user has little reaction to them during the first session, followed by a strong reaction to fear (fq.9) in the second session. Worry (fq.5;6),love (fq.4;4), pride (fq.6;4) and hope (fq.5;6) present stability, but the strongest reaction and the most stable is to sadness (fq. 7;9).

From the above, we notice that passive emotions, whether positive or negative will generally have higher stability but moderate distinguishability, while intense or incontrollable ones will have higher distinguishability frequencies. Worry is a very interesting emotion, since it presents high distinguishability and stability in all subjects. This would make it a very good authentication credential. Pleasure, however, seems to elicit almost no response, so we would consider not using it. Each user has a different set of emotions he is particularly responsive to.

We include a result interpretation table for the large 24 subject group for distinguishability, for channels 1, 2 and 3. Each cell corresponds to the representation in 'emotional words' of the corresponding signal - the ones highlighted in white mean that the emotion was non-distinguishable, green means distinguishable but not stable, and blue means stable and distinguishable in all three recording sessions. Each row in the table corresponds to a recording session. The channels 1, 2 and 3 presented the highest stability and distinguishability rate. 
Figure 2 Frequency with which different emotions could be distinguished (see online version for colours)
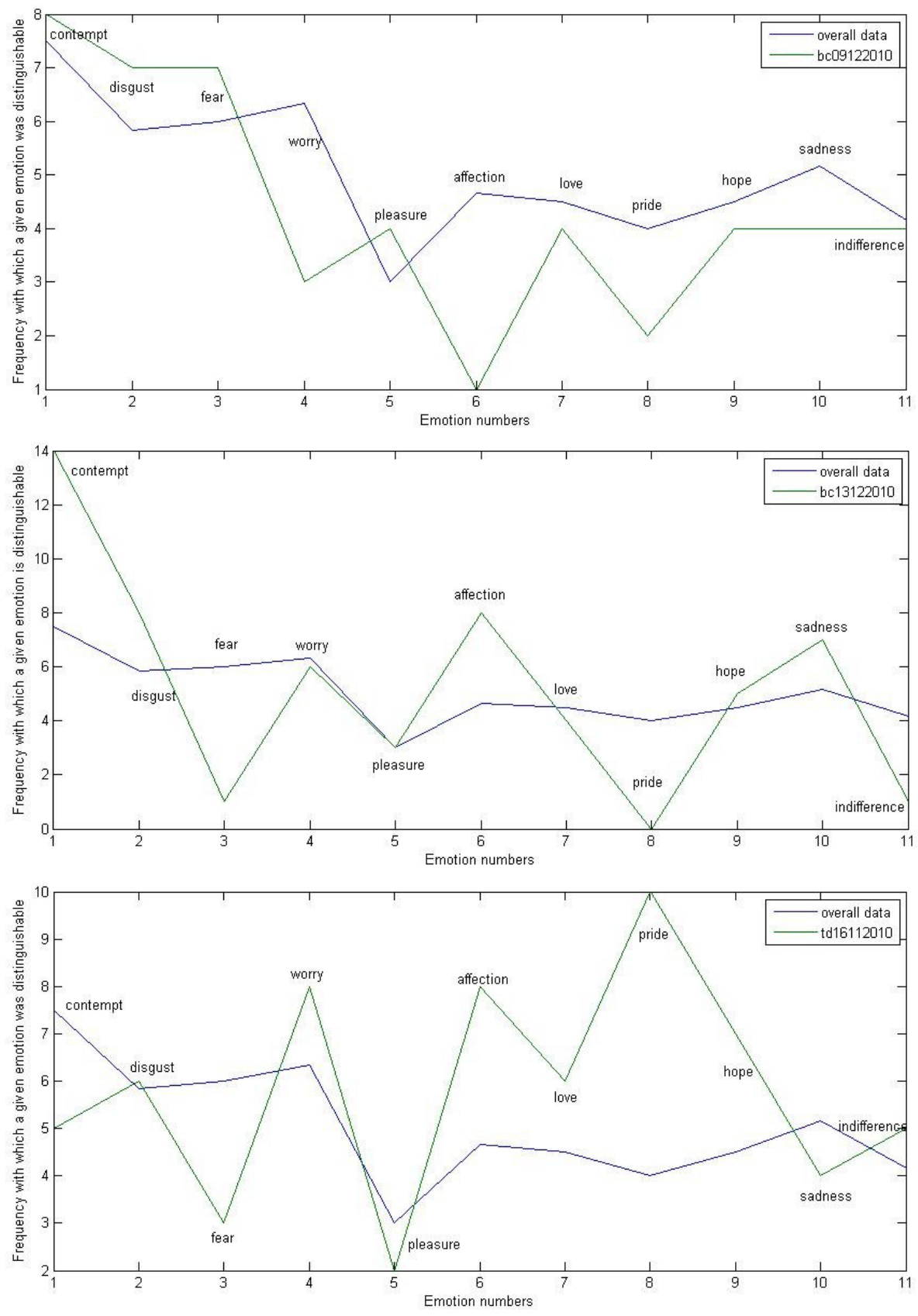
Figure 2 Frequency with which different emotions could be distinguished (continued) (see online version for colours)
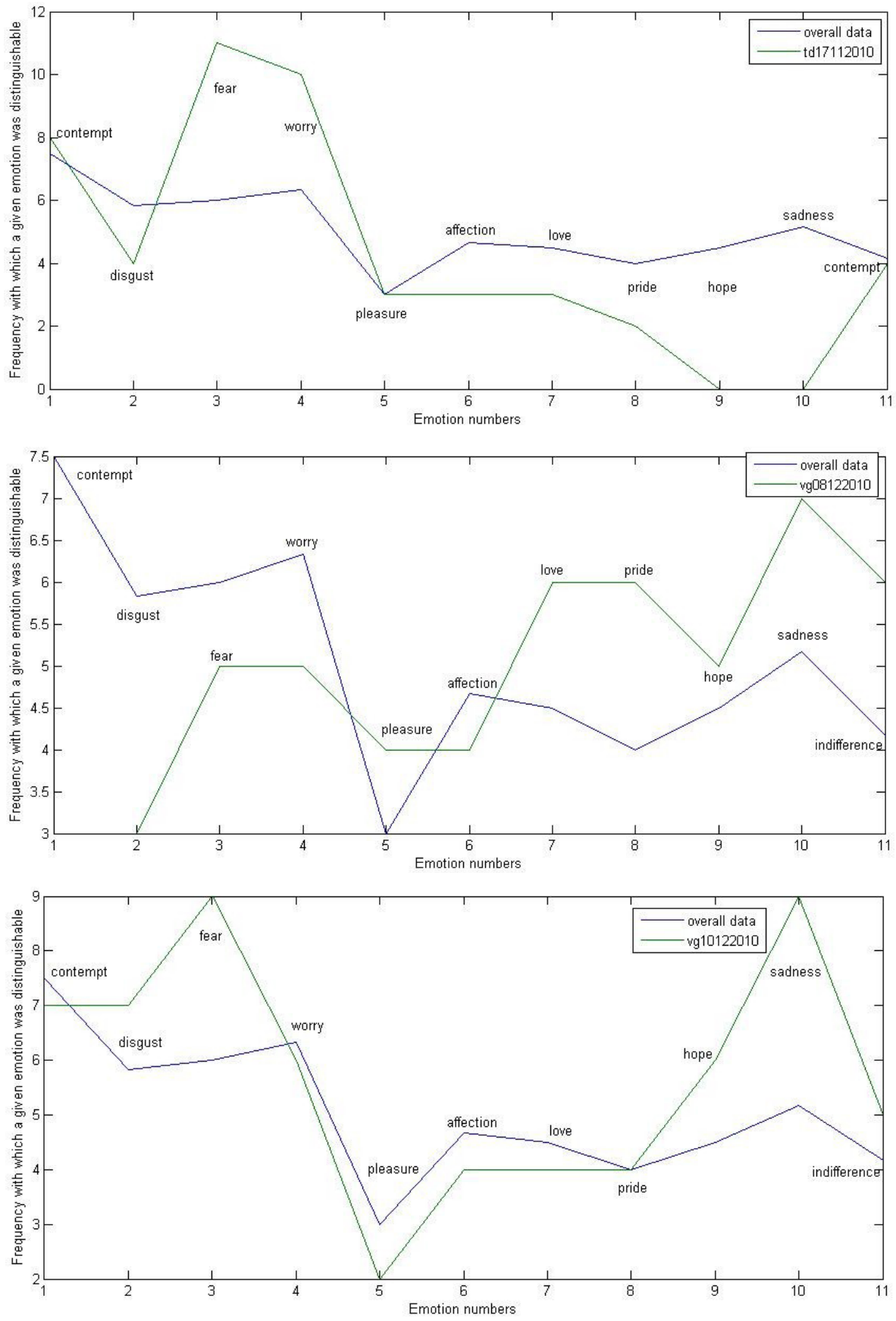
These figures (Figure 3) were used to extract the patterns in the second part of the following section. As to what concerns observations, comparing these results with the ones on the first test group, we notice that negative emotions are indeed more accurate stimuli to evaluate the emotional state of the user.

Younger subjects tended to have contained, calm reactions to negative stimulation, whereas those middle-aged, especially those undergoing specific problems had strong emotional responses to negative stimulation. The younger subjects presented stronger responses to pleasure, but an overall less intense emotional response to stimuli.

\subsection{Activation patterns}

We continue by analysing which channels are involved in the cortical representation of a given emotion. We try to detect the channels that are activated constantly when a certain emotion is triggered, since these should be the ones taken into account when performing authentication.

We select the channels that appeared in the cortical representation of emotions of at least $50 \%$ of the subjects, and build the brain activation patterns for the given emotions.

Figure 3 Distinguishable emotions for 24 subjects (see online version for colours)

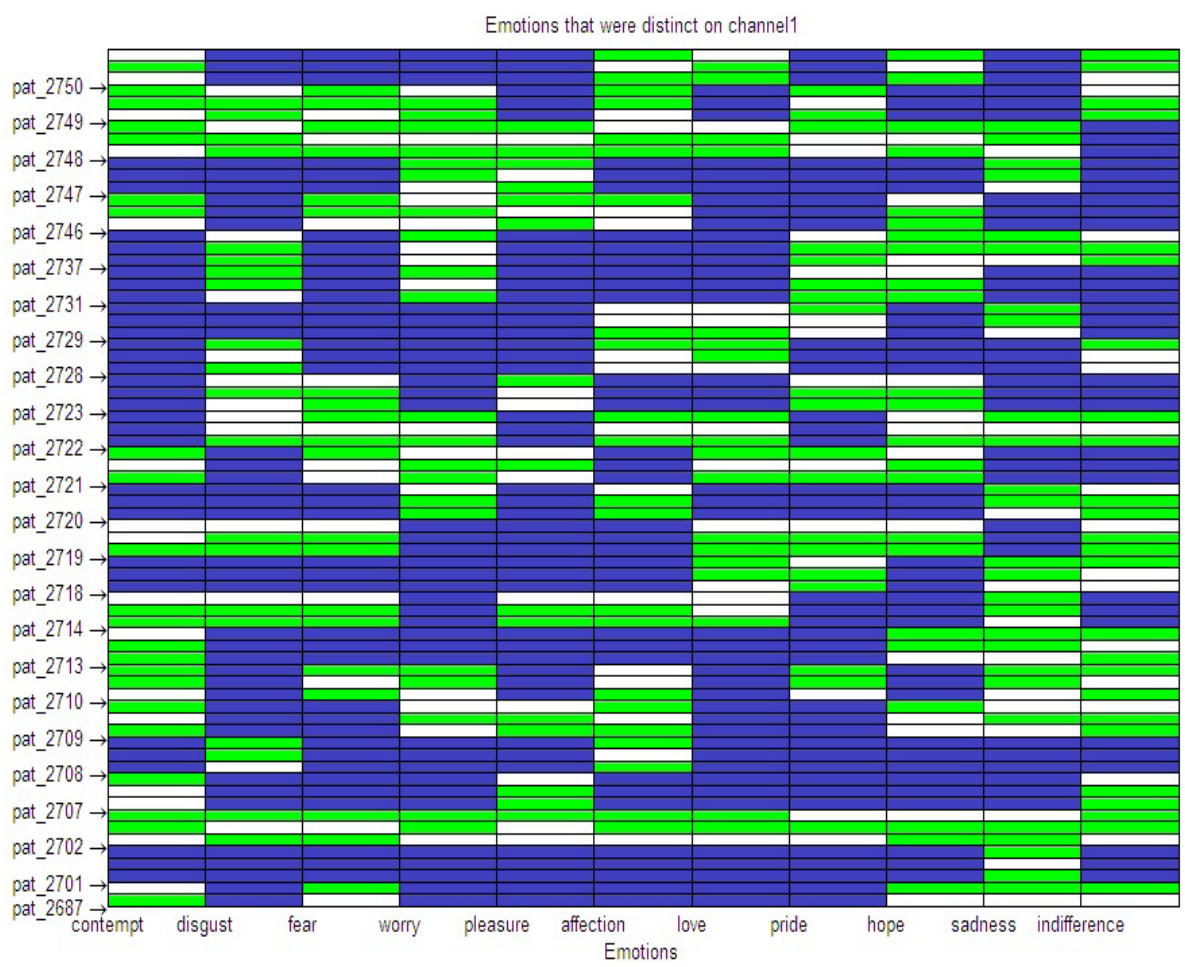


Figure 3 Distinguishable emotions for 24 subjects (continued) (see online version for colours)

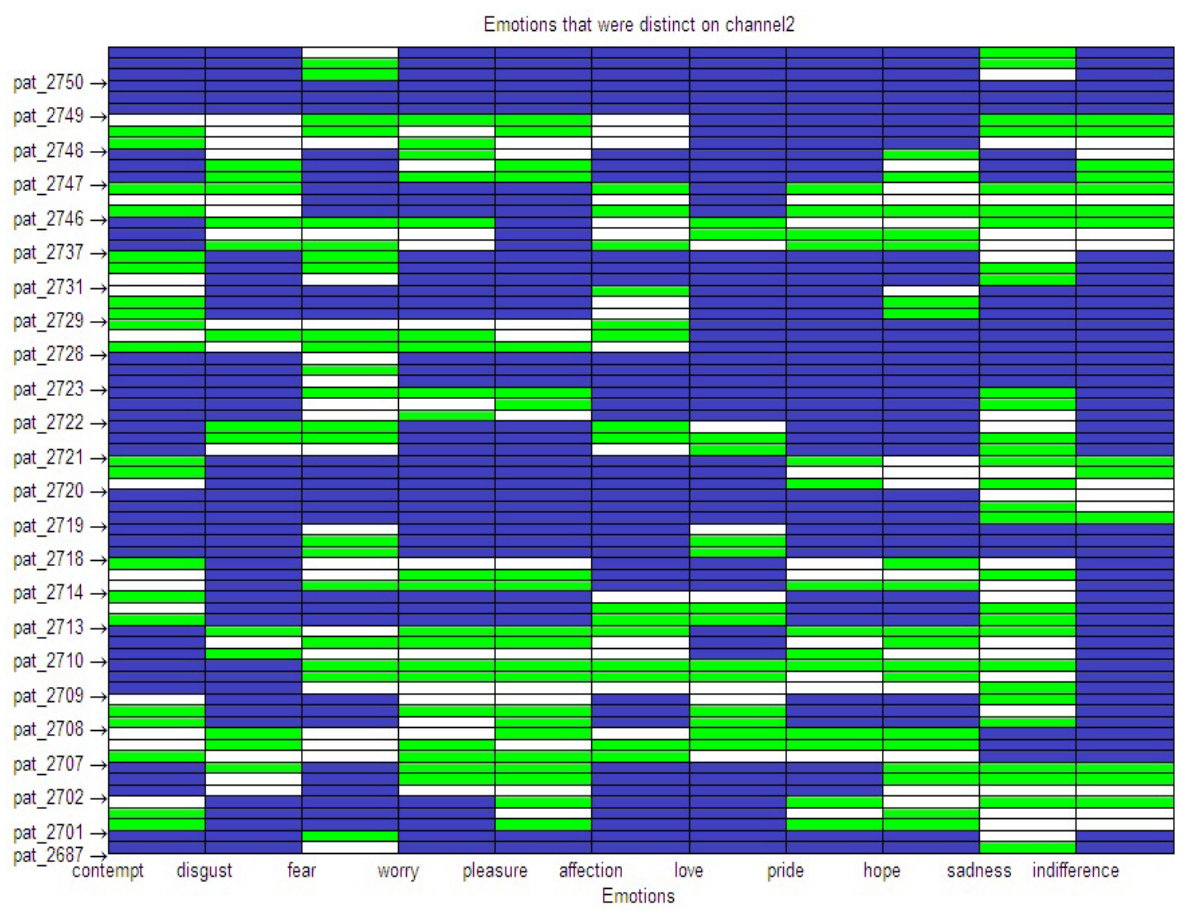

Emotions that were distinct on channel 3

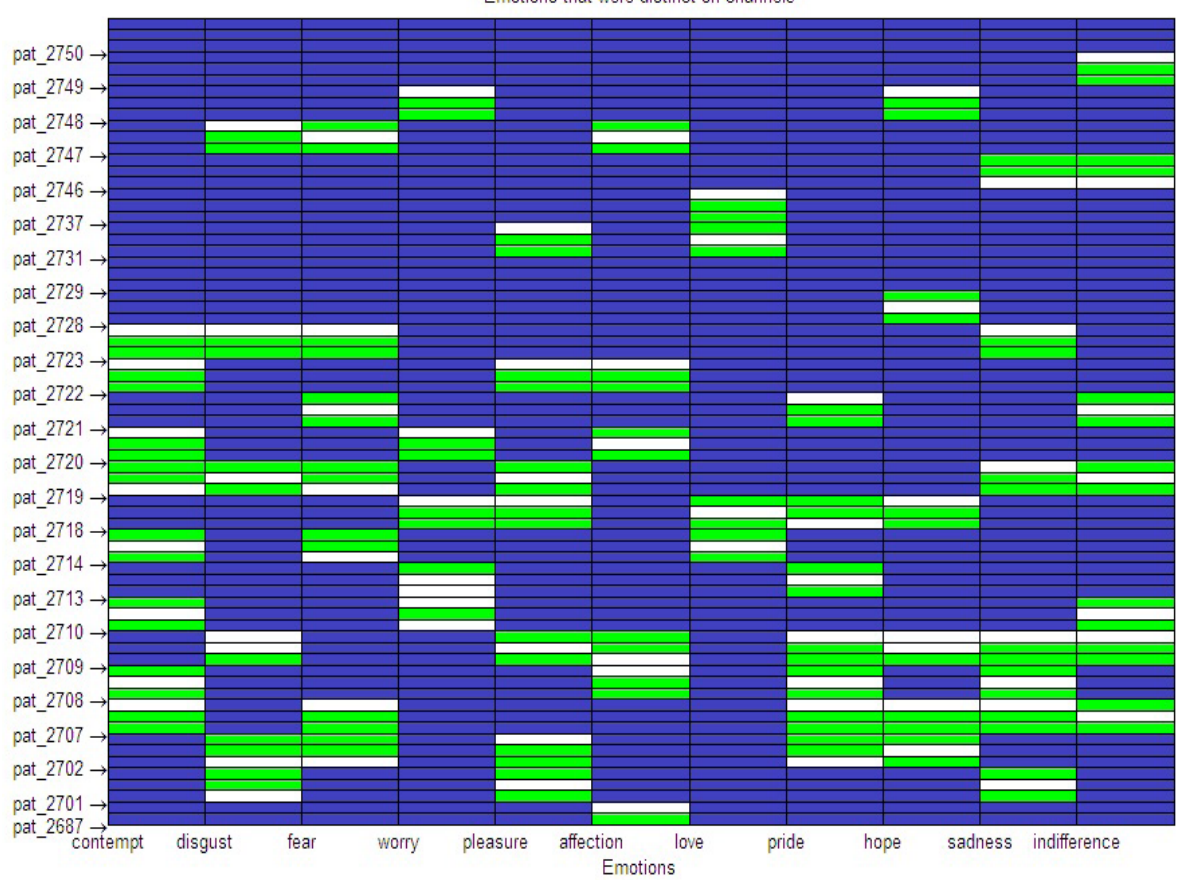


We begin by analysing the negative emotions (Figure 4) - contempt, disgust, fear, worry and sadness. We add indifference as well, for comparison.

Figure 4 Emotion patterns for five subjects, (a) contempt (b) disgust (c) fear (d) worry (e) pleasure (f) affection (g) love (h) pride (i) hope (j) sadness (k) indifference (see online version for colours)

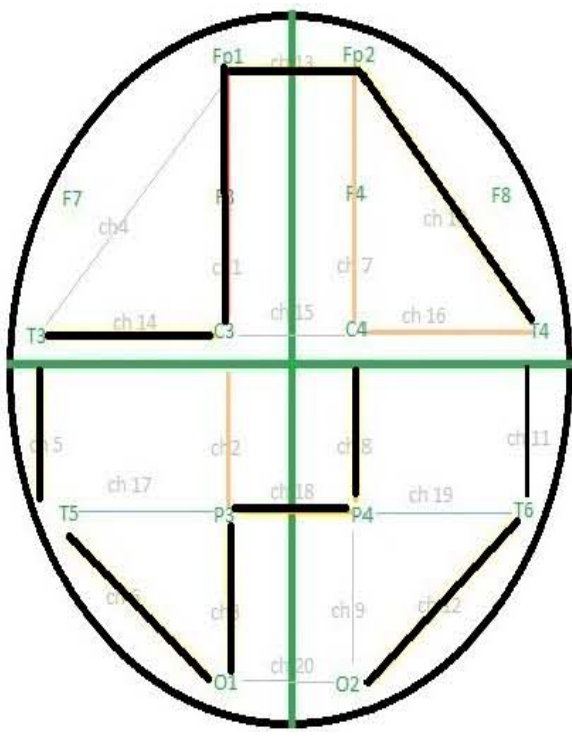

(a)

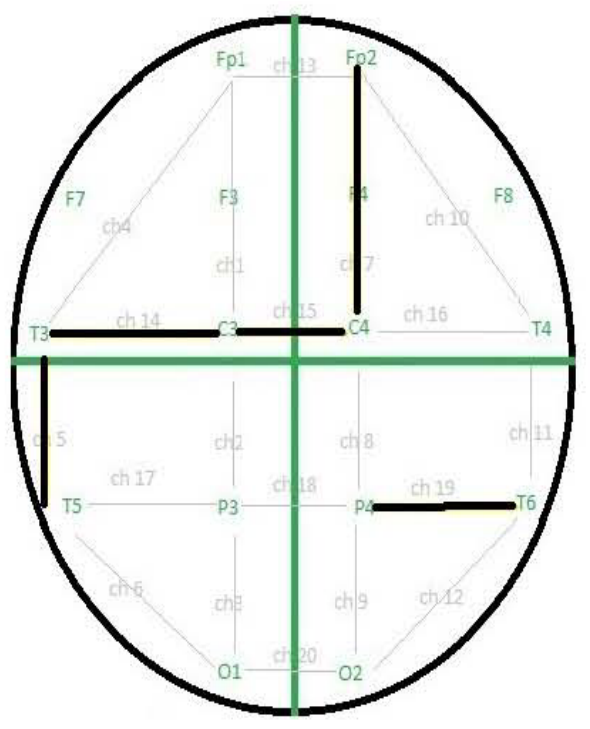

(c)

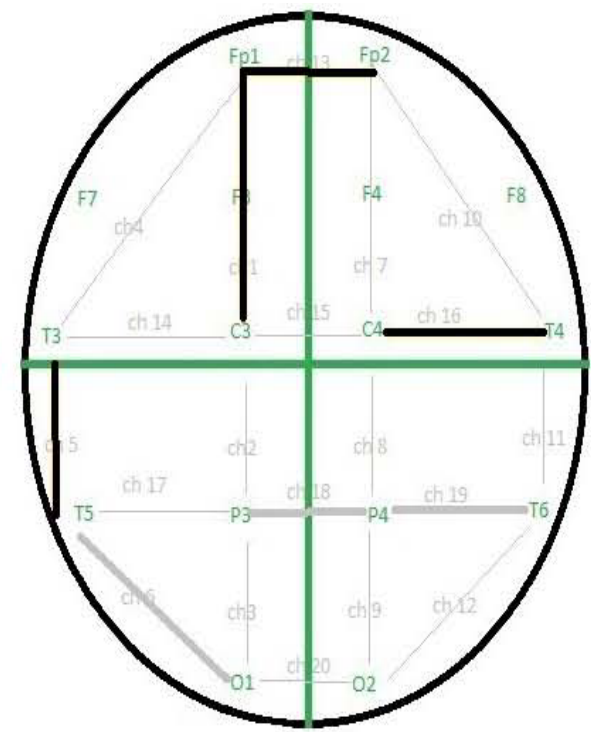

(b)

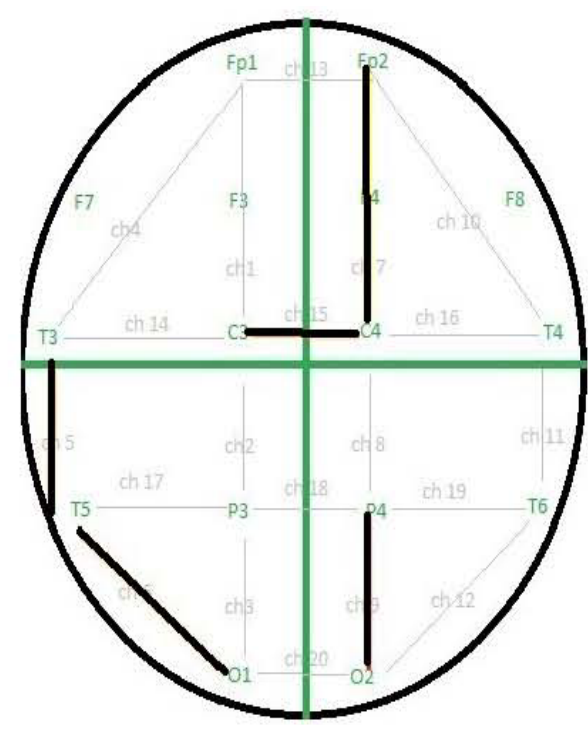

(d) 
Figure 4 Emotion patterns for five subjects, (a) contempt (b) disgust (c) fear (d) worry (e) pleasure (f) affection (g) love (h) pride (i) hope (j) sadness (k) indifference (continued) (see online version for colours)

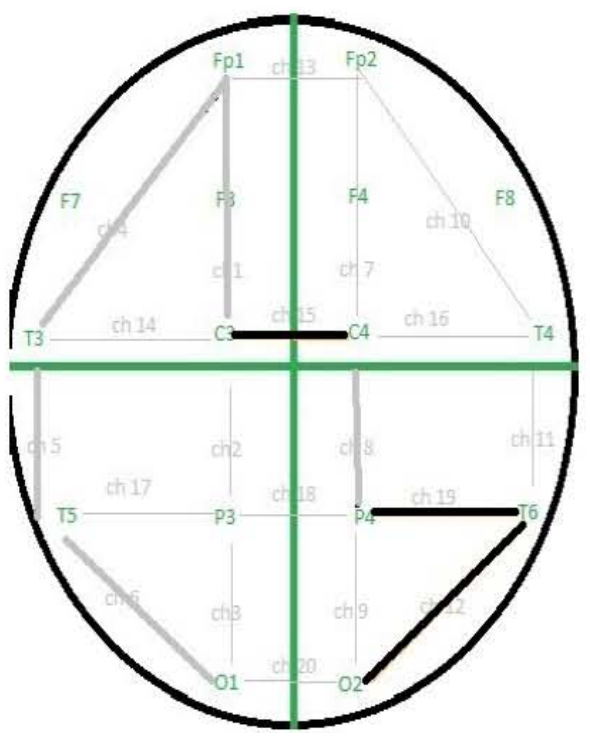

(e)



(g)

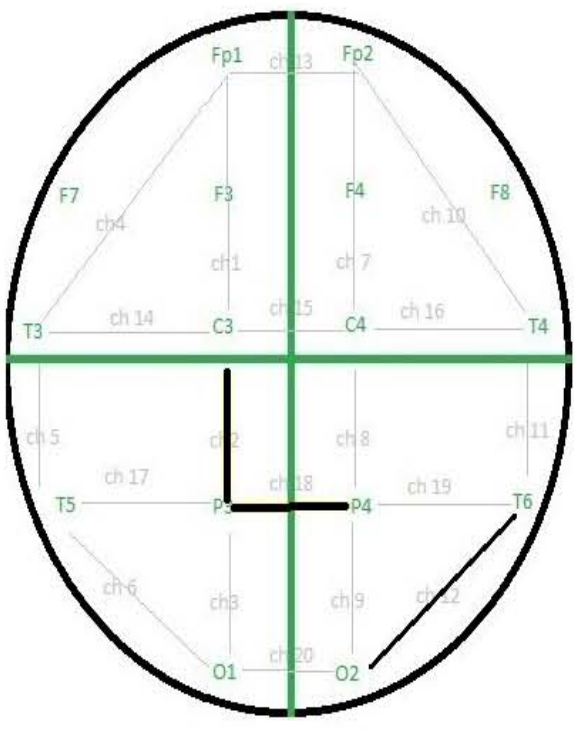

(f)

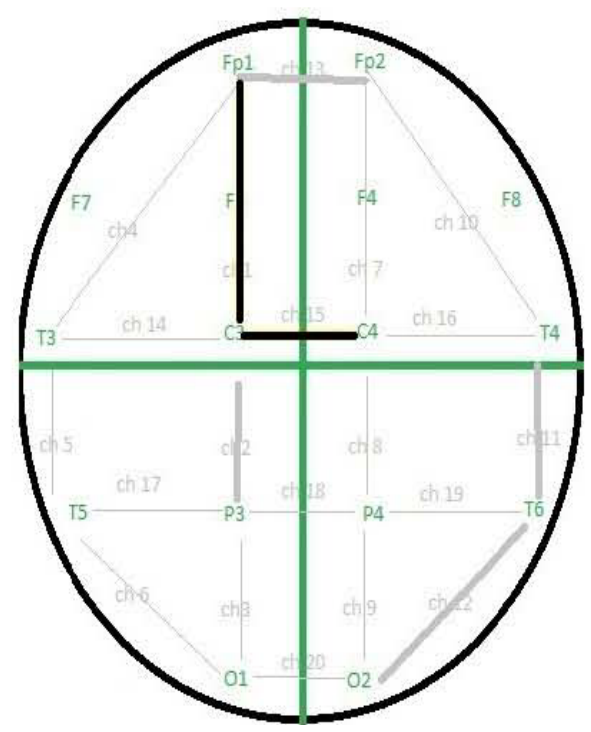

(h) 
Figure 4 Emotion patterns for five subjects, (a) contempt (b) disgust (c) fear (d) worry (e) pleasure (f) affection (g) love (h) pride (i) hope (j) sadness (k) indifference (continued) (see online version for colours)

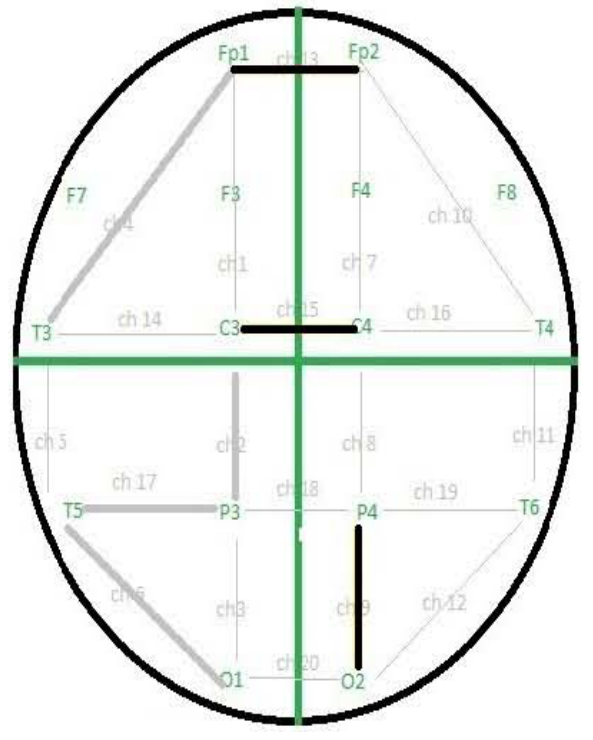

(i)

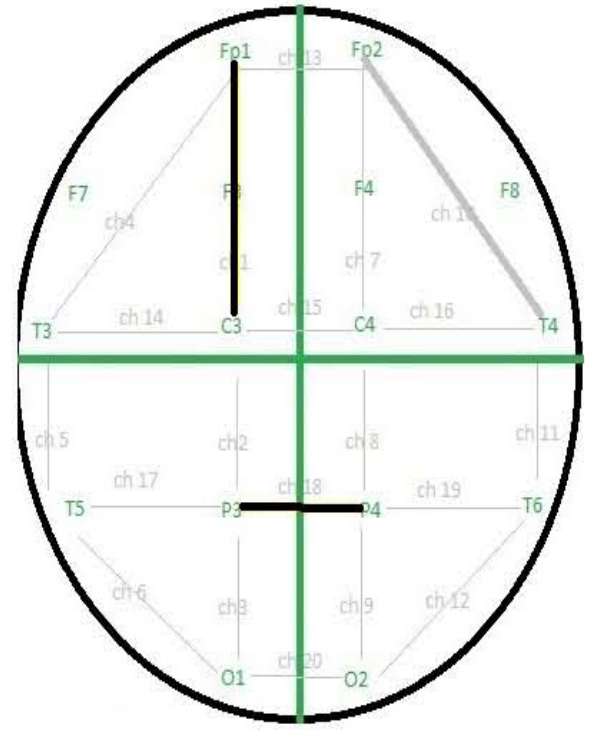

(j)

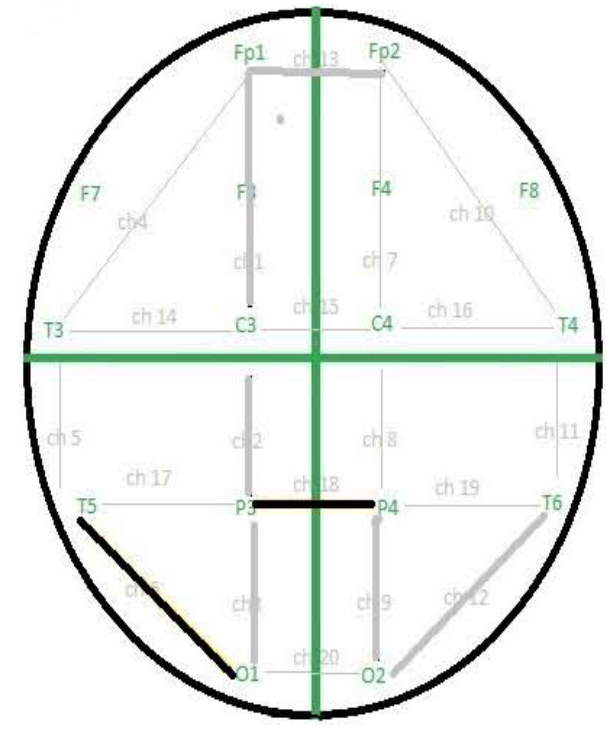

(k) 
Firstly, we notice that the intense, active negative emotions (contempt, disgust, fear and worry) are all related to the activation of the left superior temporal gyrus (channel $5=$ T3T5), which is related to language processing in right-handed persons. This contains Broadmann's area, which marks the primary auditory cortex and Wernicke's area, which is related to processing speech semantics. It is also involved in social cognition and emotional perception, which naturally relates it to the given emotions, which are to a certain degree socially conditioned (we demonstrated in Section 2 that fear can be learned socially via a given language). Also, the temporal lobe contains the hippocampus, and is important in the formation of long-term memory, which we needed in order to elicit emotions in the absence of anticipation.

We then notice that contempt and disgust (intense negative) activate the left superior frontal cortex, whereas fear and worry (incontrollable negative) activate the right superior frontal cortex. Fear and worry (anxiety) overlap in that they are both strongly aversive states related to threat. Whereas fear is linked to coping behaviour, namely avoidance and flight from perceptible threat, anxiety is 'unresolved fear' - anticipation of potentially unavoidable threat (Epstein, 1972). In Ohman (2008), the neuroanatomy of fear is related to the amygdala, midbrain periaqueductal grey, insula and anterior circulate cortex. The anterior cingulate cortex projects to the rostral temporal gyrus, midorbtitofrontal cortex, lateral prefrontal cortex, anterior insular cortex, premotor cortex and orbitofrontal cortex. In Hecht (2010), a correlation is made between the strong activation of the right hemisphere and negative emotions. In consequence, this justifies our observation that fear and worry activate channels Fp2C4 (lateral prefrontal) and C3C4 (premotor cortex). Negative emotions also activate the temporal parietal and posterior parietal cortex, that are involved in complex planning, respectively in producing planned movements and spatial orientation, which would relate to the flight and avoidance behaviour triggered by fear and anxiety, and the attempt to find solutions to the causes of disgust and contempt. In Ketter et al. (1995), a correlation is made between happiness and decreased activity in these areas. Sadness is related to increased activity in the left prefrontal cortex and decreased activity in the right prefrontal cortex, which is confirmed by Ketter et al. (1995). It also activates the central parietal cortex (P3P4), which is also noticed in the case of contempt.

We continue with the analysis of positive emotions - pleasure, affection, love, pride and hope, along with indifference.

Pleasure was the least stable and least distinguishable emotion. However, it exactly the complete lack of involvement of certain channels that makes it particular. We noticed that the left frontal, left inferior temporal and left inferior parietal lobes were never activated by this emotion, in any of the subjects. This would translate into the fact that pleasure excludes sadness and does not trigger the fight-flight response. Affection was another emotion with low stability and distinguishability, presenting only activation of the central parietal cortex (C3P3, P3P4) - projection from amygdala, and no activation of the right inferior parietal cortex (T6O2). Pleasure and affection are states that the person will attempt to maintain by not altering the environment that produces them. In consequence, there is no activation of the premotor cortex.

Love, pride and hope, on the other hand, all activate channel C3C4, the premotor cortex, since these emotions urge the person to interact with the environment. Love and pride both involve left frontal lobe activation, and no activity in the right temporal lobe and on channel C3P3. Hope however produces no activation of the left hemisphere, but some activation on channel P4O2, meaning planned movement. Indifference shows no 
particular activation of either hemisphere, and particularly not of the superior left hemisphere.

The evaluation of the results on the 24 subject test group results in the emotional patterns is presented below. We ignored channels 17, 18, 19 and 20 because in the arrangement using $\mathrm{Pz}$ as reference electrode these are not relevant to us.

We notice that the active negative emotions produce a stable, strong response in channels 1, 2 and 3 (namely Fp1Pz, F3Pz, C3Pz). They have the strongest activation of channel 3, especially worry, followed by disgust, which also dominates channel 2, among the four emotions, whereas fear does not activate it.

Figure 5 Emotion patterns for 24 subjects, (a) contempt (b) disgust (c) fear (d) worry; for the positive emotions: (e) pleasure (f) affection (g) love (h) pride; (i) hope

(j) sadness (k) indifference (continued) (see online version for colours)

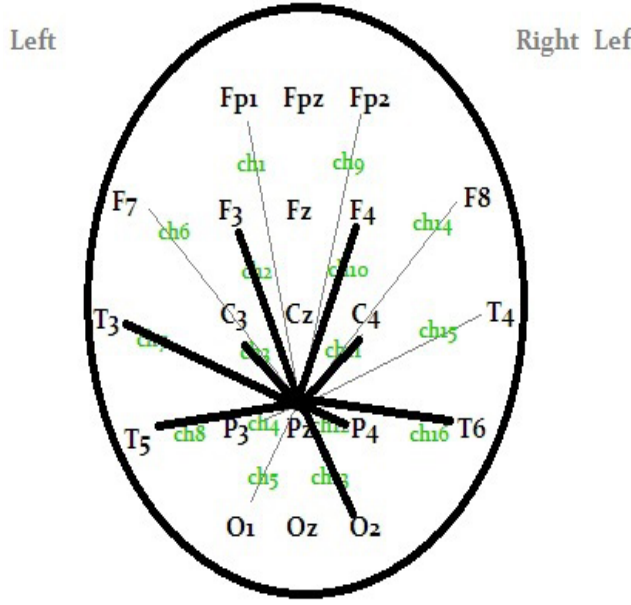

(a)

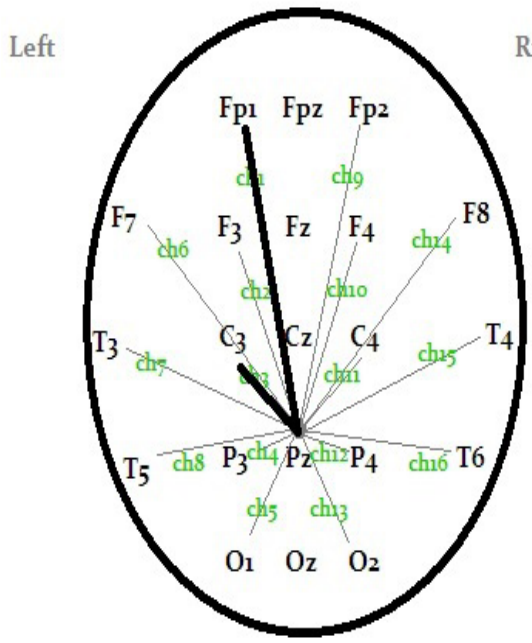

(c)

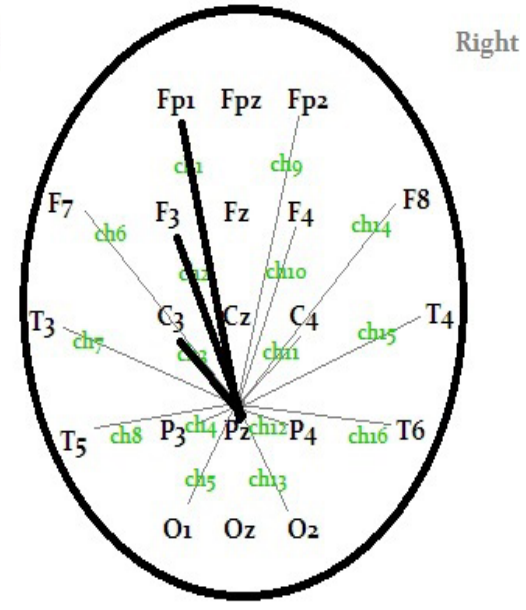

(b)

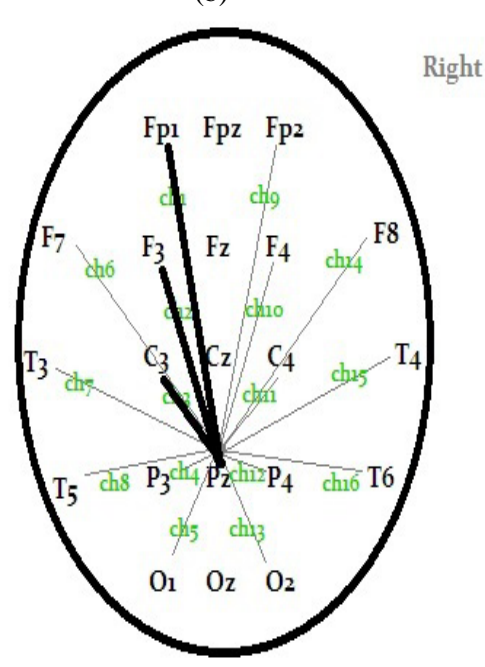

(d) 
Figure 5 Emotion patterns for 24 subjects, (a) contempt (b) disgust (c) fear (d) worry; for the positive emotions: (e) pleasure (f) affection (g) love (h) pride; (i) hope (j) sadness (k) indifference (continued) (see online version for colours)

Left

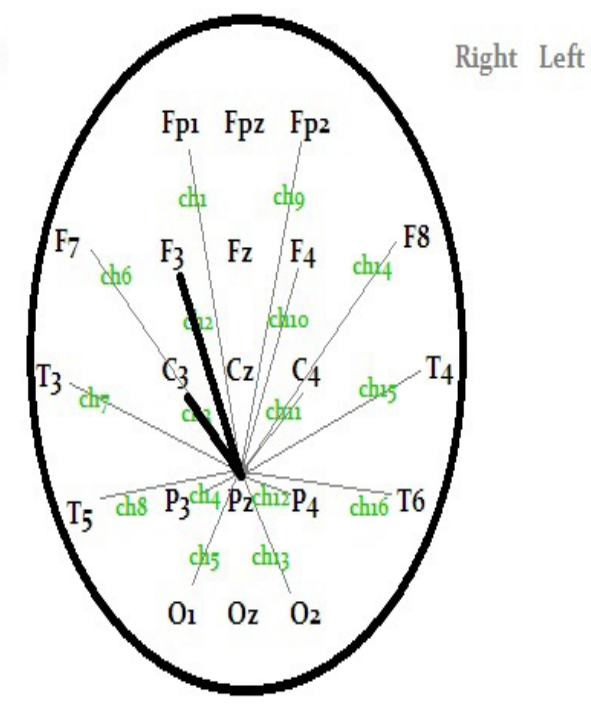

(e)

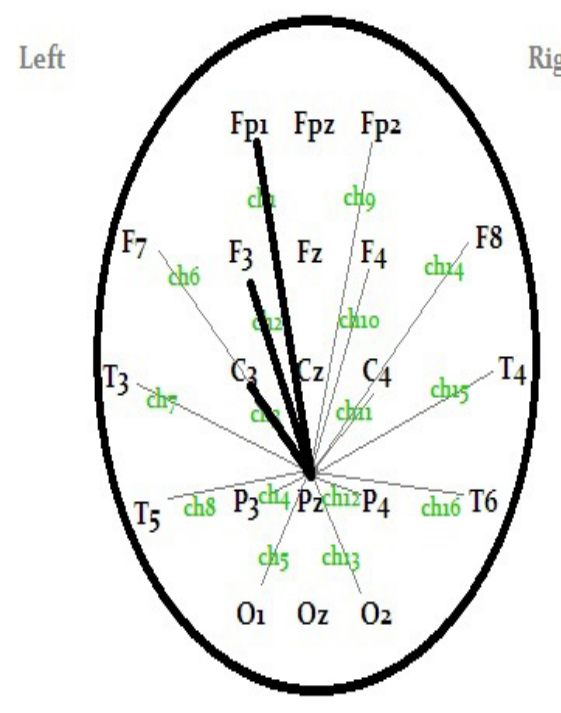

(g)

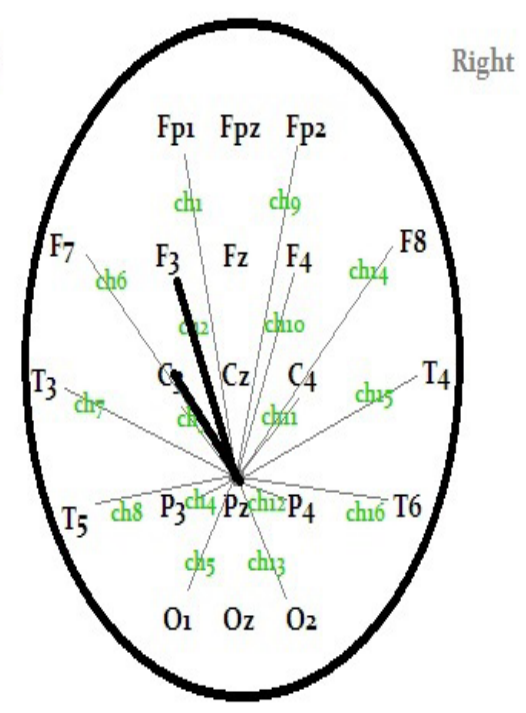

(f)

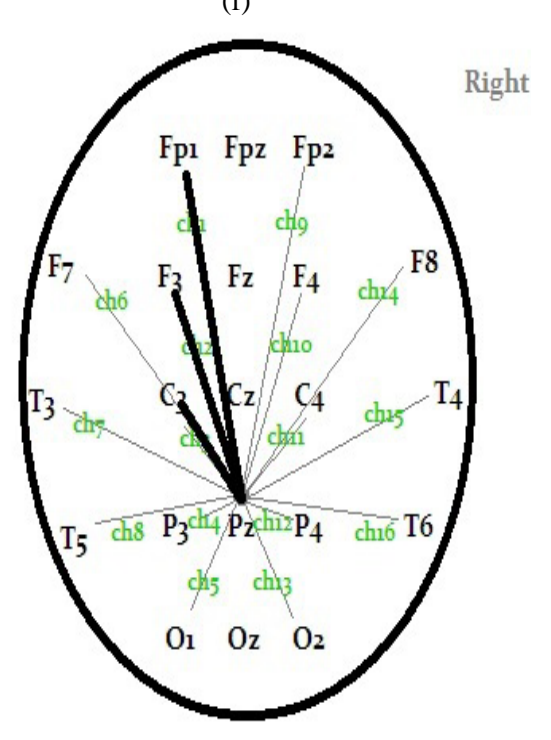

(h) 
Figure 5 Emotion patterns for 24 subjects, (a) contempt (b) disgust (c) fear (d) worry; for the positive emotions: (e) pleasure (f) affection (g) love (h) pride; (i) hope (j) sadness (k) indifference (continued) (see online version for colours)

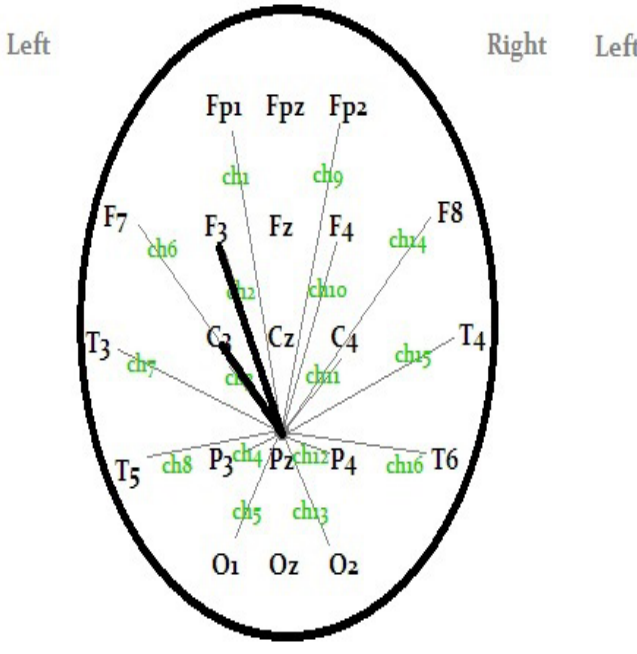

(i)

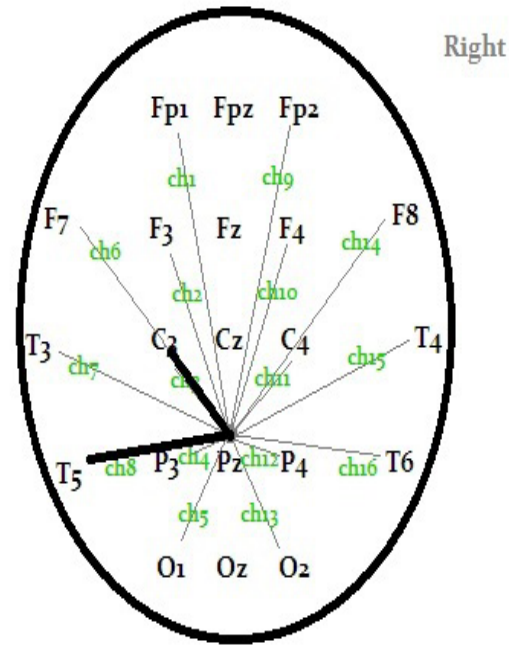

(j)

Left

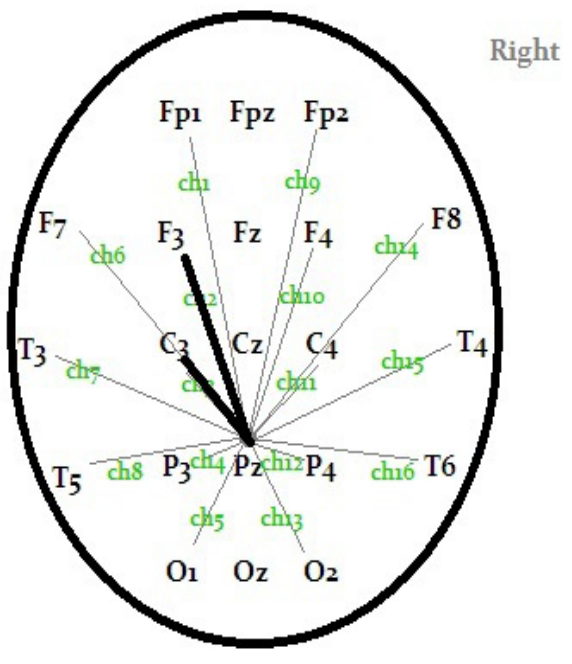

(k)

As a note, we remind the fact that although the same channel may be part of the activation pattern of two or more different emotions, the features that marked the channel as distinguishable are different, thus the translation in terms of EEG signal is very different. 
We exemplify below, with the PSD translations of all 12 centroid labels ['emotional words' (Tulceanu, 2012)], for subject bc09122010, contempt vs. disgust on channel Fp1Pz and contempt vs. sadness on channel C3Pz.

Figure 6 Translation of emotional words to PSD (see online version for colours)
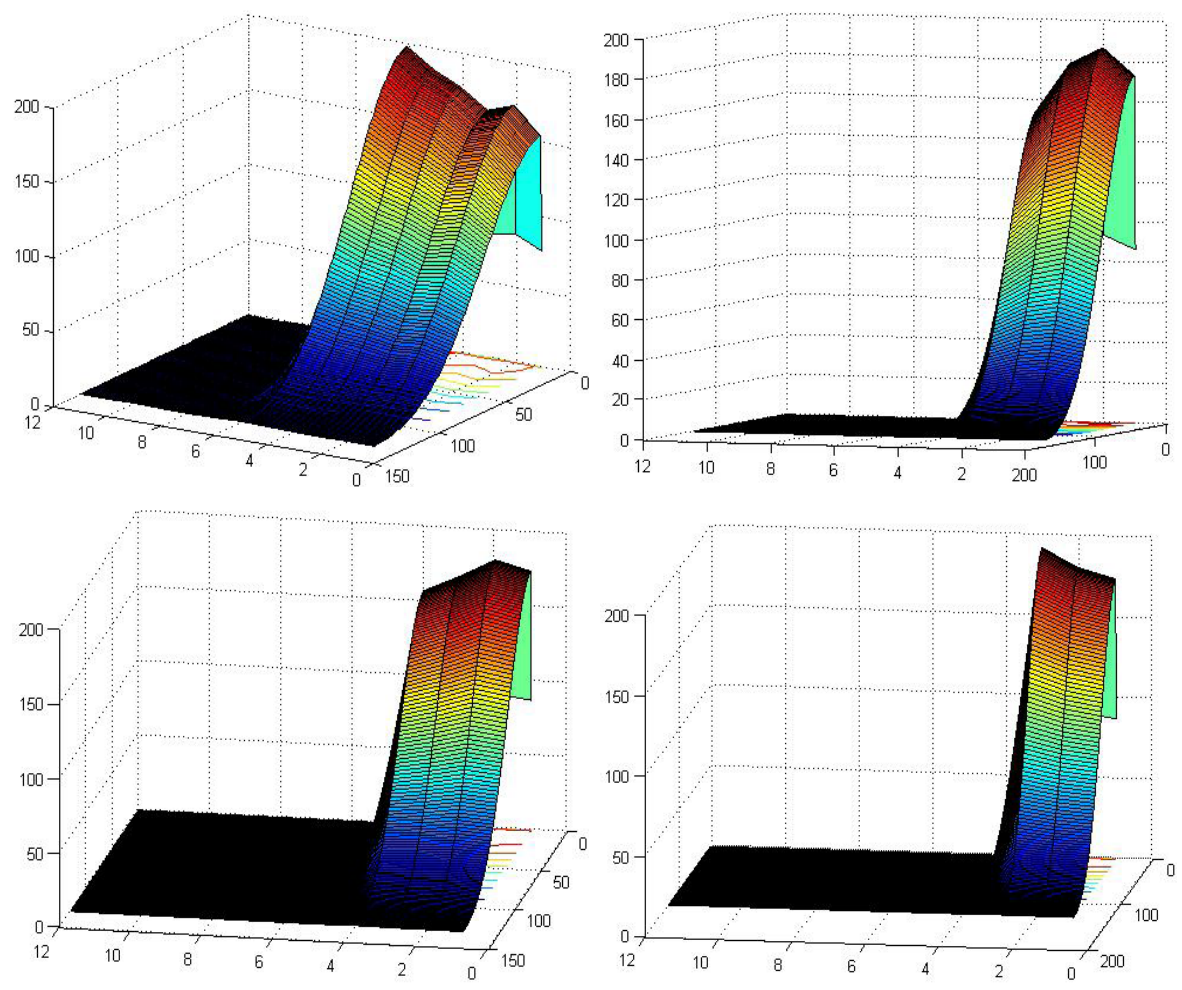

\subsection{Authentication evaluation}

The signal was processed in the same manner as for the preliminary tests, and we use the same representations for the data - a 3D matrix containing all the 'emotional word' representations of the responses to the stimuli, and a 4D matrix with their translations to the corresponding PSDs (via $f$ function in Tulceanu, 2012).

For each recording from every subject, we calculated on each channel which emotions were distinguishable. We then highlighted the stable emotions, tightening Remark 3 in the sense that an emotion was considered stable if it was distinguishable in all three recording sessions.

For authentication evaluation we consider an instantiation of the authentication scheme where the emotional challenge set consists of emotionally charged words, one corresponding to one of the emotions we have mentioned above, in the same order we used in this paper: contempt, disgust, fear, worry, pleasure, affection, love, pride, hope, sadness and indifference. 
The generic activation patterns are the ones described in the previous section, for the 24 user group. Thus, we expect the activation of channels in the following set (each group separated by comma encodes an emotional pattern by activated channel numbers):

$$
\begin{aligned}
\text { GenericActivationPattern }= & \{\{2,3,7,8,10,11,12,16\} ; \\
& \{1,2,3\} ;\{1,3\} ;\{1,2,3\} ; \\
& \{1,2\} ;\{1,2\} ;\{1,2,3\} ; \\
& \{1,2,3\} ;\{2,3\} ;\{3,8\} ;\{2,3\}
\end{aligned}
$$

The personal activation pattern is formed in the same manner as the generic pattern, for each emotion taking into account the channels where the response was distinguishable and stable in all three recording sessions.

For instance, for user pat2750, the personal activation pattern is the following:

$$
\begin{aligned}
\text { UserActivationPattern }(\text { pat2750) }= & \{\{2,3,5,7,8,9,10,11,13: 19\},\{1,2,3,6: 19\}, \\
& \{1,3,6: 19\},\{1,2,3,7: 19\},\{1,2,3,5,7: 19\}, \\
& \{2,3,5: 19\},\{2,3,6: 19\},\{1,2,3,6: 19\}, \\
& \{2,3,7: 19\},\{3,6: 19\},\{2,3,6: 19\}\} .
\end{aligned}
$$

whereas for user pat2749, the personal activation pattern is different:

$$
\begin{aligned}
\text { UserActivationPattern }(\text { pat2749) }= & \{\{2,3,9,12,13,14,16,19\},\{2,3,12: 17,19\}, \\
& \{2,3,11\},\{2,3,18\},\{1,2,3,13,16\}, \\
& \{2,3,11,13,14,16,18,19\},\{1,2,3,7,12,13,18\}, \\
& \{2,3,5,12: 17,19\},\{1,2,3,17,18\}, \\
& \{1,2,3,7,12: 18\},\{2,4,12,14\}\} .
\end{aligned}
$$

It is clear with the naked eye that both patterns differ from one another and that they include the generic pattern.

However, we have performed this for all users. Thus, we identified the emotions that are stable on each channel, and built a series of binary matrices, each corresponding to one user pattern ( 1 means that the emotion on the channel is distinguishable and stable).

We then calculated the distance between all matrices that express the user patterns, using the Procrustes analysis, that determines a linear transformation of the points in user pattern matrix A to optimally fit the points in matrix B. The sum of squared errors gives how well the fit was made. We have logarithmed the distance that was calculated.

We thus see that the smallest dissimilarity was with one's own pattern, and that it is possible to distinguish between user patterns given as distinguishable and stable emotional words over a set of cortical locations. Should there be two users with the same activated pattern (which is unlikely), authentication can revert to translating the pattern to PSD and even to the original signal samples.

For comparison, we also tried to use the Minkowski and Chebychev distances (we used the sum of the logarithm of the resulting matrices). The results are in Figures 8 and 9. 
Figure 7 Authentication evaluation by Procrustes analysis (see online version for colours)

\begin{tabular}{|c|c|c|c|c|c|c|c|c|c|c|c|c|}
\hline & 1 & 2 & 3 & 4 & 5 & 6 & 7 & 8 & 9 & 10 & 11 & 12 \\
\hline 10 & $-34,9450+\ldots$ & $-1.1606+0 \ldots$ & $-1.0581+0 \ldots$ & $-1,3957+0 \ldots$ & $-1.3518+0$ & $9364+0 \ldots$ & $-1.0702+0 \ldots$ & $-1.4465+0 \ldots$ & $-1.1030+0$. & $-1,2273+0 \ldots$ & I & $-1.0661+0$ \\
\hline 2 & $-1.1606+0 \ldots$ & $-34.6574+$ & $-0.6018+0 \ldots$ & $-1.1703+0 \ldots$ & $-0.9292+0$ & $3341+0 \ldots$ & $-0.7468+0 \ldots$ & $-1.0643+0 \ldots$ & $-0.9204+0 \ldots$ & $0.9107+0 \ldots$ & & $.7453+0$ \\
\hline 3 & $-1.0581+0 \ldots$ & $-0.6018+0 \ldots$ & $-36.0437+\ldots$ & $-1.0450+0 \ldots$ & -0 & $+0 . \ldots$ & & $+0 \ldots$ & & & & $-0.8967+0$ \\
\hline 4 & $-1,3957+0 . \ldots$ & -1.170 & $-1.0450+0 \ldots$ & $-34.6574+\ldots$ & $-1.2695+0 \ldots$ & $32+0 \ldots$ & $+0 \ldots$ & $7+0 \ldots$ & & & & $06+0$ \\
\hline 5 & $-1.3518+0 \ldots$ & $0 \ldots$ & $-0.9399+0 \ldots$ & $-1,269$ & $-34,6574+\ldots$ & $+0 \ldots$ & $+0 . .$. & $+0 \ldots$ & & & & $35+0$ \\
\hline 6 & $-0.9364+0 . \ldots$ & $-0.8341+0 \ldots$ & $-0.6830+0 \ldots$ & $-0.8832+0 \ldots$ & $-0.6607+0 \ldots$ & & $2+0 \ldots$ & $+0 \ldots$ & $+0 . .$. & & $+0 \ldots$ & $71+0$ \\
\hline 7 & $-1.0702+0 . \ldots$ & $-0.7468+0 \ldots$ & $-1,0002+0 \ldots$ & $-0.9982+0 \ldots$ & $-1.2846+0 \ldots$ & $+0 \ldots$ & $-35,3505+\ldots$ & $+0 \ldots$ & $-1,12$ & $+0 \ldots$ & $+0 \ldots$ & $35+0$ \\
\hline 8 & $-1.4465+0 \ldots$ & $0 . \ldots$ & $-0.8178+0 \ldots$ & $-1.2777+0 \ldots$ & -1.11 & & $+0 \ldots$ & $7+\ldots$ & & & $+0 \ldots$ & $2+0$ \\
\hline 9 & $-1.1030+0 \ldots$ & $-0.9204+0 \ldots$ & $-1.1313+0 \ldots$ & $-1.2122+0 \ldots$ & $-0.9225+0 \ldots$ & $+0 \ldots$ & $-1.1271+0$ & $5+0 \ldots$ & $-34,2519+\ldots$ & -1.21 & $+0 \ldots$ & $12+0$ \\
\hline 10 & $-1.2273+0 \ldots$ & $-0.9107+0 \ldots$ & $-0.9225+0 \ldots$ & $-1.1095+0 \ldots$ & -1.15 & & $+0 \ldots$ & $+0 \ldots$ & -1.21 & & & $9+0$ \\
\hline l & $-1,378$ & $-1.1445+0 \ldots$ & $-0.8227+0 \ldots$ & -1.144 & -1.130 & & -1.00 & $+0 \ldots$ & -1.00 & $-1,30$ & $000 \ldots$ & $-0.9962+0$ \\
\hline ? & $-1.0661+0 \ldots$ & $-0.7453+0 \ldots$ & $-0.8967+0 \ldots$ & $-0.9306+0 \ldots$ & $-1,1035+0 \ldots$ & $+0 . \ldots$ & $+0 \ldots$ & $+0 \ldots$ & $+0 . .$. & $+0 \ldots$ & $0 \ldots$ & $1574+$ \\
\hline & -1.32 & -1.15 & $+0 \ldots$ & -1.191 & -1.1 & & $0 \ldots$ & & $-1,12$ & & & $1+0$ \\
\hline & -1.338 & $-1,2959+0 \ldots$ & $-0.9158+0 \ldots$ & $-1,247$ & $-1.2549+0 \ldots$ & $+0 . .$. & $+0 \ldots$ & $+0 \ldots$ & -1.225 & $+0 \ldots$ & $0 \ldots$ & $22+0$ \\
\hline 15 . & -1.102 & $-0.7929+0 \ldots$ & $-0.8229+0 \ldots$ & $-0.9739+0 \ldots$ & $-1.0346+0 \ldots$ & $+0 \ldots$ & $+0 . .$. & $+0 \ldots$ & $-1.0519+0 \ldots$ & $+0 \ldots$ & $+0 \ldots$ & $-1.3651+0$ \\
\hline 1 & $-1.0056+0 \ldots$ & $-0.9332+0 \ldots$ & $-0.7295+0 \ldots$ & $-1.0287+0 \ldots$ & $-0.9921+0 \ldots$ & $+0 \ldots$ & $-1.1264+0 \ldots$ & $+0 \ldots$ & -1.173 & $+0 \ldots$ & $0 \ldots$ & $49+0$ \\
\hline $1 /$ & $-0.7055+0 \ldots$ & $-0.6949+0 \ldots$ & $-0.5879+0 \ldots$ & $-0.6312+0 \ldots$ & $-0.9254+0 \ldots$ & $+0 \ldots$ & $-0.6395+0 \ldots$ & $+0 \ldots$ & $-0.7855+0 \ldots$ & $-1,0300+0 \ldots$ & $+0 \ldots$ & $-1.0446+0$ \\
\hline 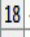 & $-0.9481+0 \ldots$ & $-0.8064+0 \ldots$ & $-0.7648+0 \ldots$ & $-0.8458+0 \ldots$ & $-1.1285+0 \ldots$ & $+0 \ldots$ & $-0.9467+0 \ldots$ & $+0 \ldots$ & $-1,3228+0 \ldots$ & -1.053 & -0.9 & $22+0$ \\
\hline 19. & $-1.1670+0 \ldots$ & $-1.0239+0 \ldots$ & $-0.8610+0 \ldots$ & $-1.1085+0 \ldots$ & $-1,3186+0 \ldots$ & $+0 \ldots$ & $-1.0782+0 \ldots$ & $+0 \ldots$ & $-1.1220+0 \ldots$ & $-1.1548+0 \ldots$ & $+0 \ldots$ & $-1.2288+0$ \\
\hline 20 & $-1.0695+0 \ldots$ & $-0.9563+0 \ldots$ & $-0.7757+0 \ldots$ & $-0.9680+0 \ldots$ & $-1.2822+0 \ldots$ & -0.8 & $-1,3646+0 \ldots$ & $+0 . .$. & $-1.1138+0 \ldots$ & -1.072 & $-1,3$. & $-0.9331+0$ \\
\hline 21. & $-1,2361+0 \ldots$ & $-1.0804+0 \ldots$ & $-0.8015+0 \ldots$ & $-1.0933+0 \ldots$ & $-1.0664+0 \ldots$ & $-0.8640+0 \ldots$ & $-1,3816+0 \ldots$ & $-1,3269+0 \ldots$ & $-0.9897+0 \ldots$ & $-1.2288+0 \ldots$ & $-1.0863+0 \ldots$ & $-0.9376+0$ \\
\hline $\mathbb{2 L}$ & $-1.0722+0 . \ldots$ & $-0.7857+0 . \ldots$ & $-0.8182+0 \ldots$ & $-0.9095+0 \ldots$ & $-0.9730+0 \ldots$ & $+0 .$. & $-0.8432+0 \ldots$ & $-0.9864+0 \ldots$ & $-0.9901+0 \ldots$ & $-1.0635+0 \ldots$ & $-0.9135+0 \ldots$ & $-1.0222+0$ \\
\hline 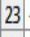 & $-0.5351+0 \ldots$ & $-0.4055+0 \ldots$ & $-0.5610+0 \ldots$ & $-0.4654+0 \ldots$ & $-0.4872+0 \ldots$ & $-0.5620+0 \ldots$ & $-0.5495+0 \ldots$ & $-0.5853+0 \ldots$ & $-0.5619+0 \ldots$ & $-0.4409+0 \ldots$ & $-0.4513+0 \ldots$ & $-0.6062+0$ \\
\hline & \% & $-0.5627+0$ & -0.52 & ברוב & & S & & | & & & & \\
\hline
\end{tabular}

\begin{tabular}{|l|c|c|c|c|c|c|c|c|c|c|c|}
\hline 13 & 14 & 15 & 16 & 17 & 18 & 19 & 20 & 21 & 22 & 23 & 24 \\
\hline
\end{tabular}

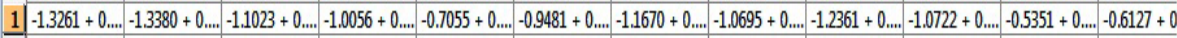

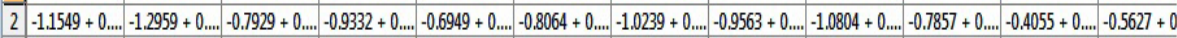

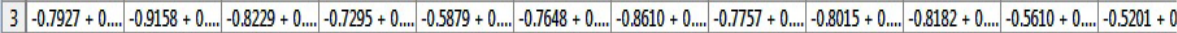

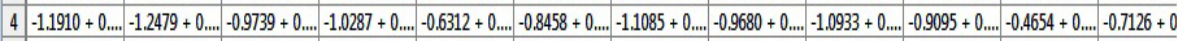

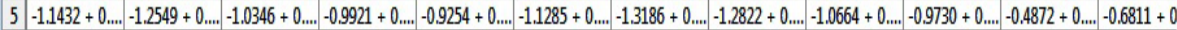

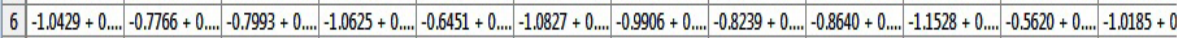

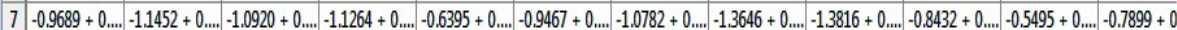

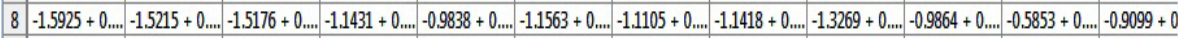

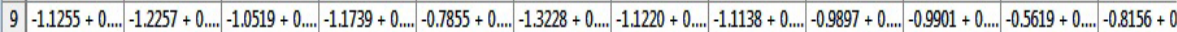

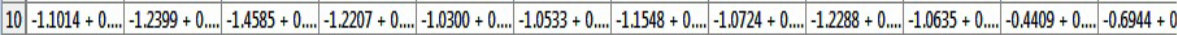

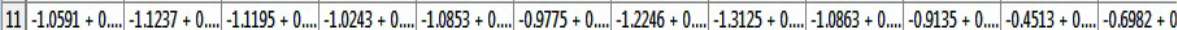

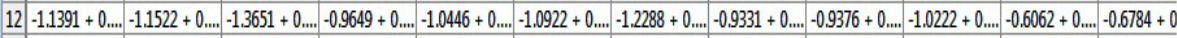

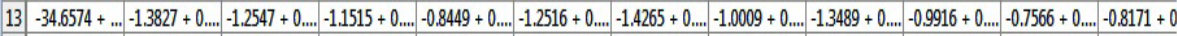

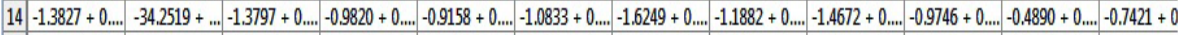

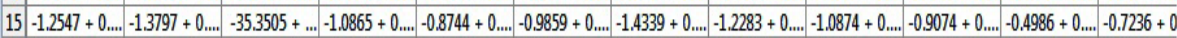

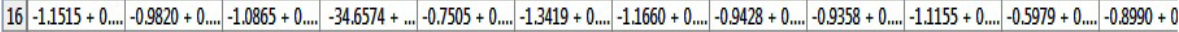

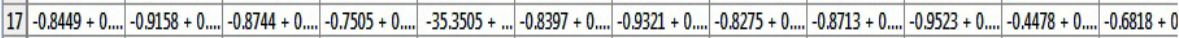

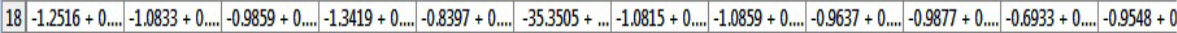

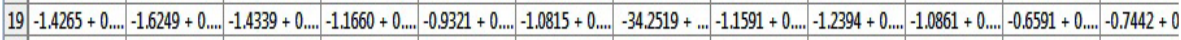

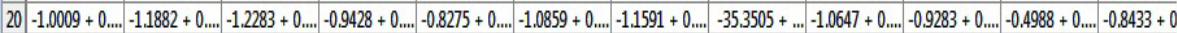

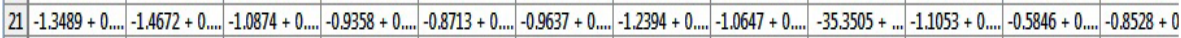

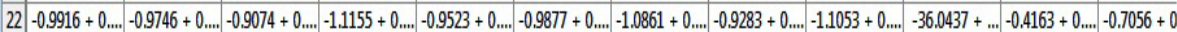

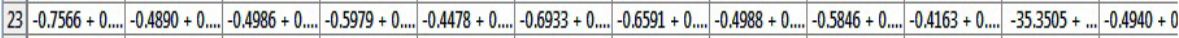

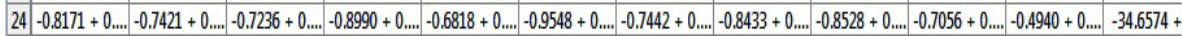


For Minkowski distances, see Figure 8.

Figure 8 Authentication evaluation by Minkowski distance (see online version for colours)

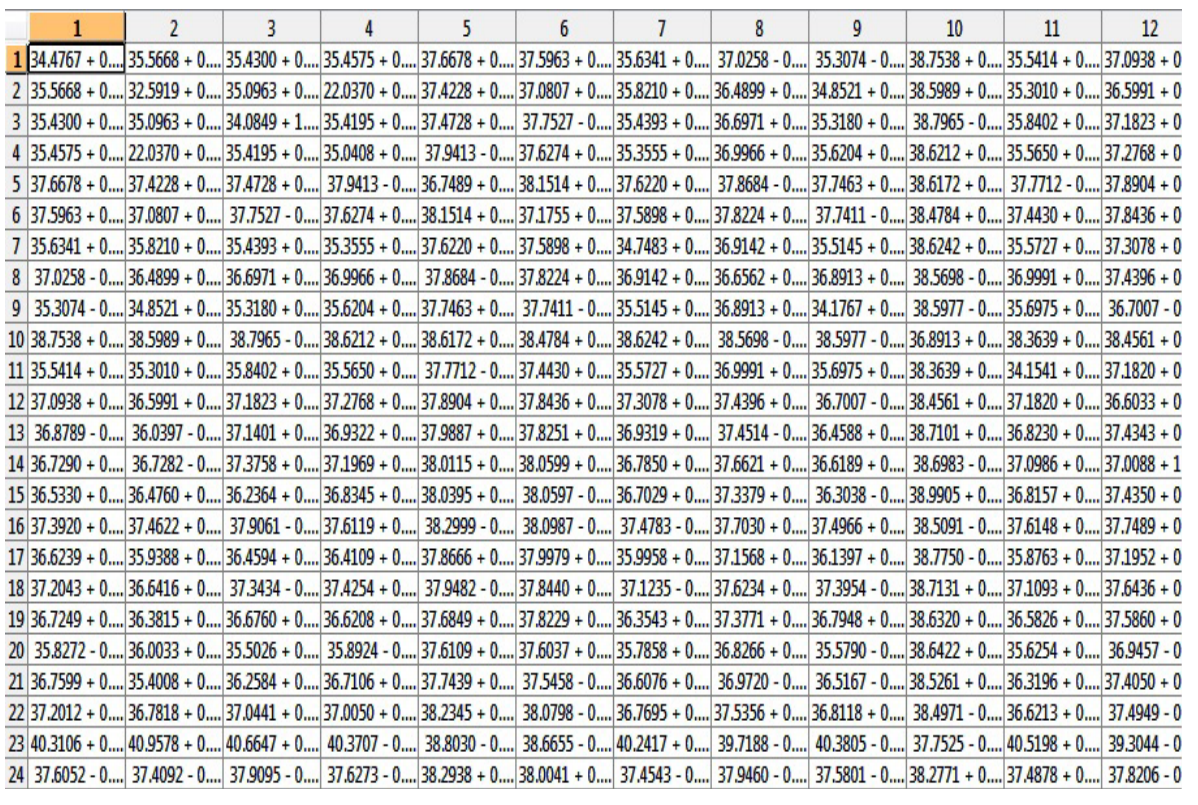

\begin{tabular}{|c|c|c|c|c|c|c|c|c|c|c|c}
\hline 13 & 14 & 15 & 16 & 17 & 18 & 19 & 20 & 21 & 22 & 23 & 24 \\
\hline
\end{tabular}

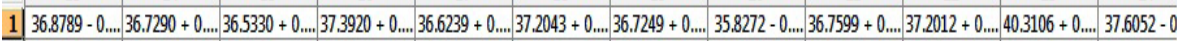

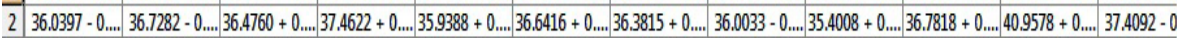

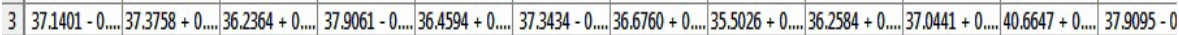

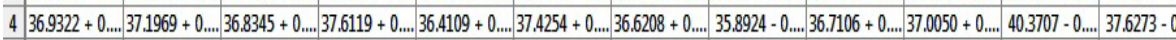

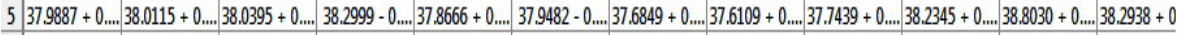

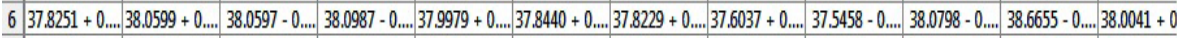

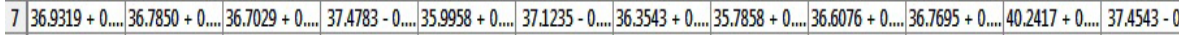

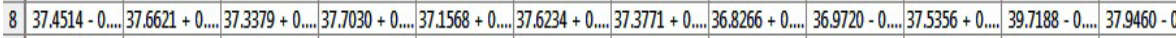

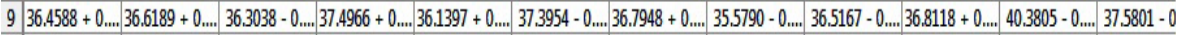

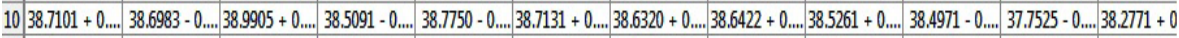

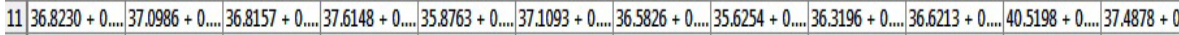

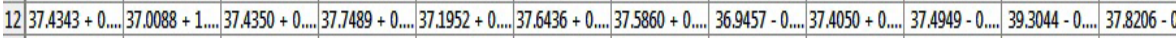
$13 \quad 36.3623+0 \ldots . .37 .3496+0 \ldots . .37 .2509+0 \ldots . .37 .7164+0 \ldots . .36 .9962+0 \ldots . .37 .4685+0 \ldots . .37 .4141+0 \ldots . .37 .1918+0 \ldots . .36 .8472-0 \ldots . .37 .4029+0 \ldots . .39 .8435+0 \ldots . .37 .7056+0$

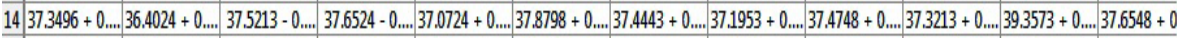
$1537.2509+0 \ldots . .37 .5213-0 \ldots . .35 .7614+0 \ldots . .37 .7085+0 \ldots . .37 .0409+0 \ldots 37.3083+0 \ldots . .37 .1359+0 \ldots . .36 .5805+0 \ldots . .37 .0922+0 \ldots . .37,3832-0 \ldots . .39 .8332-0 \ldots . .37 .7908+0$ $1637.7164+0 \ldots . . .37 .6524-0 \ldots . .37 .7085+0 \ldots . .36 .8926+0 \ldots . .37 .2444+0 \ldots . .37 .6544+0 \ldots . .37 .8150+0 \ldots . .37 .3079+0 \ldots .37 .7726+0 \ldots . .37 .5050+0 \ldots . .38 .8325+0 \ldots . .37 .7791-0$ $1736.9962+0 \ldots . .37 .0724+0 \ldots . .37 .0409+0 \ldots . .37 .2444+0 \ldots . .35 .0280+0 \ldots . .37 .2545+0 \ldots . .36 .8628-0 \ldots . .36 .3333+0 \ldots . .37 .0004+0 \ldots . .37 .0574-0 \ldots . .40 .2022+0 \ldots . .37 .4068-0$ $1837.4685+0 \ldots . .37 .8798+0 \ldots . .37 .3083+0 \ldots . .37 .6544+0 \ldots . .37 .2545+0 \ldots . .36 .4538+0 \ldots . .37 .3088+0 \ldots . .37 .3179+0 \ldots .37 .3174+0 \ldots . .38 .1812-0 \ldots . .39 .4575-0 \ldots . .37 .8232+0$ $1937.4141+0 \ldots 37.4443+0 \ldots . .37 .1359+0 \ldots . .37 .8150+0 \ldots 36.8628-0 \ldots 37.3088+0 \ldots . .36 .2631+0 \ldots . .36 .9127+0 \ldots .37 .1916+0 \ldots . .37 .4624+0 \ldots . .39 .5571-0 \ldots . .37 .7921-0$ $2037.1918+0 \ldots . .37 .1953+0 \ldots . .36 .5805+0 \ldots . .37 .3079+0 \ldots . .36 .3333+0 \ldots 37.3179+0 \ldots . .36 .9127+0 \ldots . .34 .8190+0 \ldots .36 .4906+0 \ldots . .36 .8164+0 \ldots . .40 .0432+0 \ldots . .37 .4982+0$ $2136.8472-0 \ldots 37.4748+0 \ldots . .37 .0922+0 \ldots . .37 .7726+0 \ldots 37.0004+0 \ldots 37.3174+0 \ldots . .37 .1916+0 \ldots . .36 .4906+0 \ldots .35 .2543+0 \ldots . .36 .8559-0 \ldots . .39 .9354-0 \ldots . .37 .8441-0$ $2237.4029+0 \ldots . .37 .3213+0 \ldots . .37 .3832-0 \ldots . .37 .5050+0 \ldots . .37 .0574+0 \ldots . .38 .1812-0 \ldots . .37 .4624+0 \ldots . .36 .8164+0 \ldots . .36 .8559-0 \ldots . .35 .1585+0 \ldots . .39 .3755+0 \ldots . .37 .5768-0$

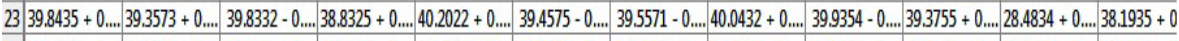

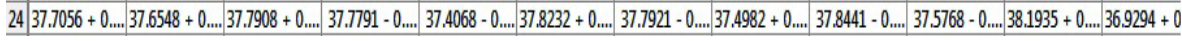


For Chebychev distance, see Figure 9.

Figure 9 Authentication evaluation by Chebychev distance (see online version for colours)

\begin{tabular}{|c|c|c|c|c|c|c|c|c|c|c|c|c|}
\hline & 1 & 2 & 3 & 4 & 5 & 6 & 7 & 8 & 9 & 10 & 11 & 12 \\
\hline 1 & $25,3284-0 . \ldots$ & $3.0949 \mathrm{e}+26 \ldots$ & $9.8164 \mathrm{e}+16 \ldots$ & $\mathrm{NaN}+\mathrm{NaNi}$ & $26.3768-0 \ldots$ & $26.3768-0 \ldots$ & $26.3768-0 \ldots$ & $26.3768-0 . \ldots$ & $26.3768-0 \ldots$ & $26.3768-0 \ldots$ & $\mathrm{NaN}+0.02 \ldots$ & $26.3768-0$ \\
\hline 2 & $\mathrm{NaN}+\mathrm{NaNi}$ & i $25.3284-0 . \ldots$ & $26.3768-0 \ldots$ & $26.3768-0 \ldots$ & $26.3768-0 \ldots$ & $26.3768-0 \ldots$ & $26.3768-0 \ldots$ & $26.3768-0 . \ldots$ & $\mathrm{NaN}+\mathrm{NaNi}$ & li $26.3768-0 \ldots$ & $26.2765+0 \ldots$ & $-2.2762 e+1$ \\
\hline 3 & $20.9424+0 \ldots$ & $26.3768-0 \ldots$ & $24.7078+0 \ldots$ & $26.0399+0 \ldots$ & $26.3768-0 \ldots$ & $\mathrm{NaN}+\mathrm{NaNi}$ & $\mathrm{NaN}+\mathrm{NaNi}$ & $26.3768-0 \ldots$ & $26.3768-0 \ldots$ & $6.3768-0 \ldots$ & $26.3768-0 \ldots$ & $3768-0$ \\
\hline 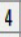 & $3.0949 \mathrm{e}+26 \ldots$ & $26.3768-0 \ldots$ & $26.0399+0 \ldots$ & 25.328 & $26.3768-0 \ldots$ & $-1,1803 e+1 \ldots$ & $\mathrm{NaN}+\mathrm{NaNi}$ & $26,3768-0 \ldots$ & $\mathrm{NaN}+\mathrm{NaNi}$ & li $26.3768-0 \ldots$ & $-1.1443 \mathrm{e}+1 \ldots$ & $26.3768-0$ \\
\hline 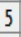 & $26.3768-0 \ldots$ & $26.3768-0 \ldots$ & $26.3768-0 \ldots$ & $26.3768-0 \ldots$ & $25.3284-0 \ldots$ & $26.3768-0 . \ldots$ & $26.3768-0 \ldots$ & $26.3768-0 \ldots$ & $26.3768-0 \ldots$ & $26.3768-0 . \ldots$ & $88-0 . \ldots$ & $5.3768-0$ \\
\hline 6 & $26.3768-0 \ldots$ & $26.3768-0 \ldots$ & $-1.1261 \mathrm{e}+1 \ldots$ & $26.2885+0 \ldots$ & $26.3768-0 . \ldots$ & $25.3284-0 \ldots$ & $26.3768-0 \ldots$ & $26.3768-0 \ldots$ & $\mathrm{V}+\mathrm{NaNi}$ & $3-0 \ldots$ & $8-0 \ldots$ & $26.3768-0$ \\
\hline 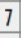 & $26.3768-0 \ldots$ & $26.3768-0 \ldots$ & $-6.7459 \mathrm{e}+1 \ldots$ & $\mathrm{NaNi}$ & $26.3768-0 \ldots$ & $8-0 \ldots$ & $4-0 \ldots$ & $26.3768-0 \ldots$ & $\mathrm{aNi}$ & $8-0 \ldots$ & & $768-0$ \\
\hline 3 & $26.3768-0 \ldots$ & $26,3768-0 \ldots$ & $26,3768-0 \ldots$ & 26.37 & $26.3768-0 \ldots$ & $26.3768-0 \ldots$ & $26.3768-0 \ldots$ & $25.3284-0 \ldots$ & $3-0 \ldots$ & $768-0 \ldots$ & $-0 . \ldots$ & $768-0$ \\
\hline 9 & $26.3768-0 \ldots$ & $\mathrm{NaN}+\mathrm{NaNi}$ & 26.3 & $0 \ldots$ & $26.3768-0 \ldots$ & $85-0 \ldots$ & $\mathrm{NaNi}$ & $26.3768-0 \ldots$ & $-0 . .$. & $88-0 \ldots$ & & $668-0$ \\
\hline 0 & $26.3768-0 . \ldots$ & $26.3768-0 \ldots$ & $26,3768-0 \ldots$ & $26,3768-0 \ldots$ & $26.3768-0 \ldots$ & $26.3768-0 \ldots$ & $26.3768-0 \ldots$ & $26.3768-0 \ldots$ & $8-0 \ldots$ & $25,3284-0 \ldots$ & $-0 . .$. & $768-0$ \\
\hline 1 & $0.02 \ldots$ & $26.2765+0 \ldots$ & $26.3768-0 \ldots$ & $\mathrm{NaNi}$ & $26.3768-0 . \ldots$ & $26.3768-0 \ldots$ & $\mathrm{NaNi}$ & $26.3768-0 \ldots$ & $2 e+1 \ldots$ & $26.3768-0 \ldots$ & $0 . .$. & $26.3768-0$ \\
\hline 2 & $26.3768-0 \ldots$ & $1.1236 \mathrm{e}+15 \ldots$ & $26.3768-0 \ldots$ & $26.3768-0 \ldots$ & $26.3768-0 \ldots$ & $26.3768-0 \ldots$ & $26.3768-0 \ldots$ & $26.3768-0 \ldots$ & $26.3768-0 \ldots$ & $26.3768-0 \ldots$ & $26.3768-0 \ldots$ & $25.3284-0$ \\
\hline 3 & $26.3768-0 . \ldots$ & $26.3768-0 \ldots$ & $26.3768-0 \ldots$ & $\mathrm{NaN}+0.02 \ldots$ & $26.3768-0 . \ldots$ & $-1.1803 e+1 \ldots$ & $26.3768-0 \ldots$ & $26.3768-0 \ldots$ & $\mathrm{NaN}+\mathrm{NaNi}$ & i $26.3768-0 . .$. & $-0 \ldots$ & $26.3768-0$ \\
\hline 4 & $26.3768-0 \ldots$ & $-2,2762 e+1 \ldots$ & $26.3768-0 \ldots$ & $26.3768-0 \ldots$ & $26.3768-0 \ldots$ & $26.3768-0 \ldots$ & $26.3768-0 \ldots$ & $26.3768-0 . \ldots$ & $26.3768-0 \ldots$ & $26.3768-0 \ldots$ & $26.3768-0 \ldots$ & $26.3768-0$ \\
\hline 5 & $26.3768-0 \ldots$ & $26.3768-0 \ldots$ & $26.2765+0 \ldots$ & $26.3768-0 \ldots$ & $26.3768-0 \ldots$ & $\mathrm{NaN}+\mathrm{NaNi}$ & $26.3768-0 . \ldots$ & $26.3768-0 \ldots$ & $26.3768-0 . \ldots$ & $26,3768-0 \ldots$ & $3-0 \ldots$ & $26.3768-0$ \\
\hline 6 & $26.3768-0 \ldots$ & $26.3768-0 \ldots$ & $26.3768-0 \ldots$ & $26.3768-0 \ldots$ & $26.3768-0 \ldots$ & $26.3768-0 \ldots$ & $26.3768-0 \ldots$ & $26.3768-0 \ldots$ & $26.3768-0 \ldots$ & $26.3768-0 \ldots$ & $26.3768-0 \ldots$ & $26.3768-0$ \\
\hline$I$ & $26.3768-0 . \ldots$ & $26.2034-0 \ldots$ & $\mathrm{NaN}+\mathrm{NaNi}$ & $26.3768-0 \ldots$ & $26.3768-0 \ldots$ & $\mathrm{NaN}+\mathrm{NaNi}$ & $26.3768-0 \ldots$ & $26.3768-0 \ldots$ & $26.3768-0 \ldots$ & $26.3768-0 \ldots$ & 263 & $24.0000+6$ \\
\hline 8 & $26.3768-0 \ldots$ & $26.2765+0 \ldots$ & $26.3768-0 \ldots$ & $26.3768-0 \ldots$ & $26.3768-0 \ldots$ & $26.3768-0 \ldots$ & $26.3768-0 \ldots$ & $26.3768-0 \ldots$ & $26.3768-0 \ldots$ & $26.3768-0 \ldots$ & $26.2765+0 \ldots$ & $26.3768-0$ \\
\hline 9 & $26.3768-0 \ldots$ & $26,3768-0 \ldots$ & $\mathrm{NaN}+\mathrm{NaNi}$ & $\mathrm{NaN}+\mathrm{NaNi}$ & $26.3768-0 \ldots$ & $26.3768-0 \ldots$ & $\mathrm{NaN}+\mathrm{NaNi}$ & $26,3768-0 \ldots$ & $26.3768-0 \ldots$ & $26.3768-0 \ldots$ & $8-0 \ldots$ & $26.3768-0$ \\
\hline 0 & $\mathrm{NaN}+\mathrm{NaNi}$ & $-1.0517 \mathrm{e}+1 \ldots$ & $\mathrm{NaN}+\mathrm{NaNi}$ & $\mathrm{NaN}+\mathrm{NaNi}$ & $26.3768-0 \ldots$ & $26.3768-0 \ldots$ & $26.3768-0 \ldots$ & $26,3768-0 \ldots$ & $26.3768-0 \ldots$ & $26,3768-0 \ldots$ & $-2.2518 \mathrm{e}+1 \ldots$ & $26.3768-0$ \\
\hline & $26.3768-0 \ldots$ & $26.3768-0 \ldots$ & $26.3768-0 \ldots$ & $26.3768-0 \ldots$ & $26.3768-0 \ldots$ & $26.3768-0 \ldots$ & $26.3768-0 \ldots$ & $26.3768-0 \ldots$ & $26.3768-0 \ldots$ & $26.3768-0 \ldots$ & $26.3768-0 \ldots$ & $26.3768-0$ \\
\hline & $26.3768-0 \ldots$ & $26.3768-0 \ldots$ & $26,3768-0 \ldots$ & $26,3768-0 \ldots$ & $26,3768-0 \ldots$ & $26.3768-0 \ldots$ & $26.3768-0 \ldots$ & $26.3768-0 \ldots$ & $26.3768-0 \ldots$ & $26.3768-0 \ldots$ & $26.3768-0 \ldots$ & $26.3768-0$ \\
\hline 3 & $26.3768-0 \ldots$ & $26.3768-0 \ldots$ & $26.3768-0 \ldots$ & $26.3768-0 \ldots$ & $26.3768-0 \ldots$ & $26.3768-0 \ldots$ & $26.3768-0 \ldots$ & $26.3768-0 \ldots$ & $26.3768-0 \ldots$ & $26,3768-0 \ldots$ & $26.3768-0 \ldots$ & $26.3768-0$ \\
\hline 4 & $20.3 / 6$ & $26.2885+0$. & $26.3768-0 \ldots$ & $26.3768-0 \ldots$ & $26.3768-0 \ldots .$. & $26.3768-0 \ldots$ & $26.3768-0 \ldots$ & $26,3 / 68-0 \ldots$ & $26.3768-0 \ldots$ & $26.3 / 68-0$ & $26.2885+0 \ldots$ & $26.3768-0$ \\
\hline
\end{tabular}

\begin{tabular}{|l|c|c|c|c|c|c|c|c|c|c|c|}
13 & 14 & 15 & 16 & 17 & 18 & 19 & 20 & 21 & 22 & 23 & 24 \\
\hline
\end{tabular}

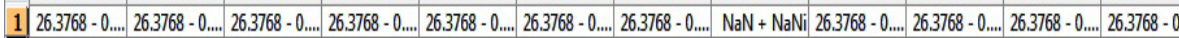

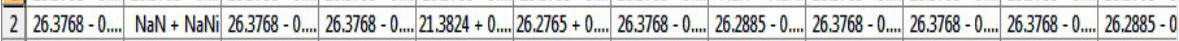

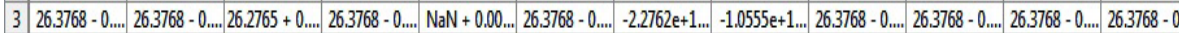

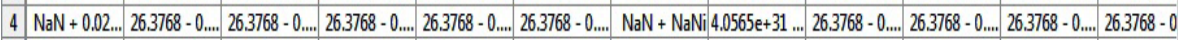

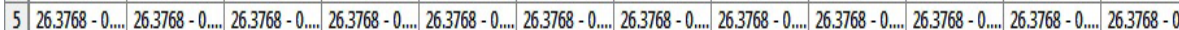

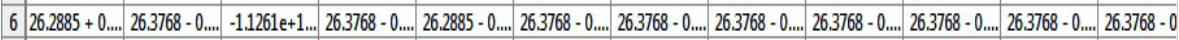

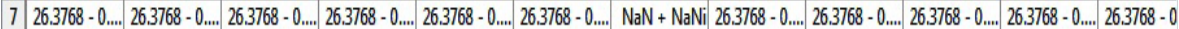

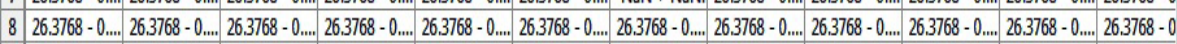



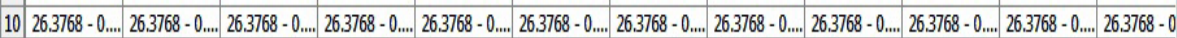

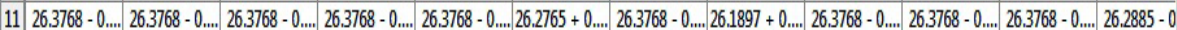

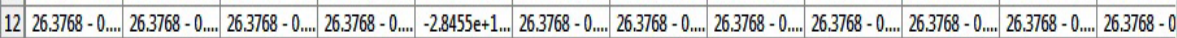

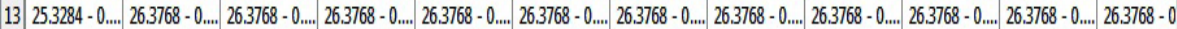

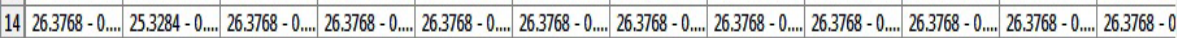

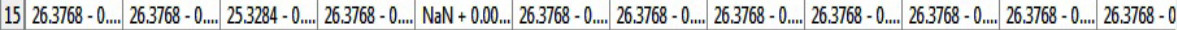

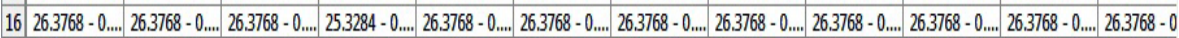

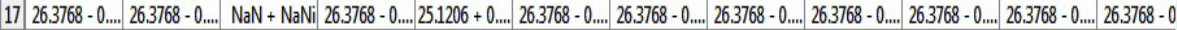

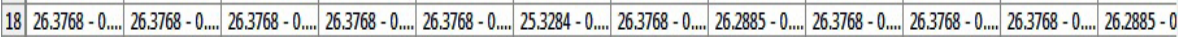



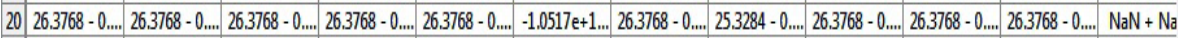

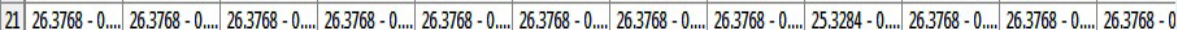

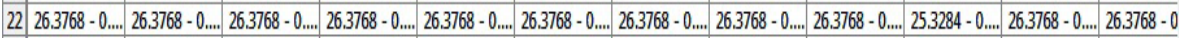

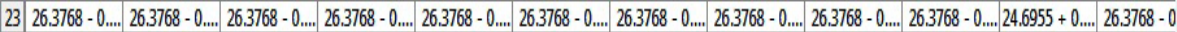

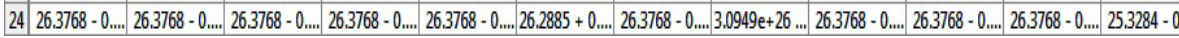


We prefer the Procustes analysis, since the other two do not express the pattern overlap accurately. Other types of distances could be further tested.

\section{Conclusions and future work}

As we began mentioning in Section 1, in this paper we attempted to answer to the following issues:

a whether emotional responses can act as credentials

b whether it is possible to trigger emotional responses using only the semantic of auditive stimuli

c which would be the suitable representations of the emotional responses

d how can we make the scheme capable of distinguishing and classifying a new emotional response

e which is the accuracy with which we can distinguish between individuals using this scheme

f how can we make the scheme capable of predicting potentially irresponsible/dangerous behaviour.

In Section 2, we have provided scientific arguments why emotional responses can act as credentials, and why it is possible to measure them by analysing the cerebral activity via EEG. We have proposed and performed an experiment that uses the semantic of auditive stimuli in order to trigger emotional responses, and we have been able to extract activation patterns for each emotion.

We have noticed that personal activation patterns are supersets of the generic activation patterns, with the potential addition of personal stable channels that were not included in the generic model (this means that they were highly personal to the user, and were not found in the activation patterns of other users, thus were not included in the generic model).

The fact that we have found to be quite much variation between the activation patterns of two different subjects may be related to the fact that we use abstract concepts for stimuli. Whereas concrete nouns seem to activate areas related to the semantic dimensions of the noun (Just et al., 2010), the dimensions associated to abstract concepts are likely to be more personal, and vary according to the associations made by different subjects.

In Section 5, we have provided a formal model for the emotional representations, and we have also assessed the performance of the given model on our dataset. For our data, the scheme allowed correct distinction between users. We have used a significant group in order to be able to have a relevant opinion, although further tests will be recommended.

The question of how we can make the scheme capable of distinguishing and classifying a new emotional response remains open. We are taking into account the model proposed by Just et al. (2010), but we think it should be suitably adapted in order to classify abstract concepts. Another option we are considering is that of extending the tree automaton we began mentioning in Section 5. An algebraic approach is another very interesting path. 
Another issue we leave as future work is how can we make the scheme capable of predicting potentially irresponsible/dangerous behaviour. Intuitively, we should record slow variations in time from the user model. However, given the limited dataset, we were unable to do that.

In order to conclude, we reiterate what we have done in this paper: we have proposed a new concept of authentication via an authentication scheme capable of extracting meta-information about the user's capacity to responsibly use the resources he gains access to from the credentials. This has applications in the military, e-learning and health areas, where it is necessary that those accessing resources and performing tasks should not only have the right to do so, but should also be in good mental state (not fatigued, unbalanced, under the influence of different substances or otherwise mentally or emotionally impaired).

We believe that using this type of authentication scheme would increase the overall safety of systems, by being able to know that any person handling sensitive resources is responsible for his own actions.

This could also prevent false claims to being irresponsible for one's decisions at a given moment.

\section{Acknowledgements}

This paper is supported by the Sectoral Operational Program Human Resources Development (SOP HRD), financed from the European Social Fund and by the Romanian Government under the contract number POSDRU/159/1.5/S/133675, Romanian Academy, Iasi Branch.

\section{References}

Bradley, M.M., Hamm, A.O., Lang, P.J. and Greenwald, M.K. (1993) 'Looking at pictures: affective, facial, visceral and behavioral reactions', Psychophisiology, Vol. 30, No. 3, pp.261-273.

Brodal, A. (1982) Neurological Anatomy, Oxford University Press, New York.

Cacioppo, J.T., Larsen, J.T. and Norris, C.J. (2003) 'Effects of positive affect and negative affect on electromyographic activity over zygomaticus major and corrugator supercilii', Psychophisiology, Vol. 40, No. 5, pp.776-785.

Epstein, S. (1972) 'The nature of anxiety with emphasis upon its relationship to expectancy', in C.D. Spielberger (Ed.): Anxiety: Current Trends in Theory and Research, Vol. 2, pp.291-337, Academic Press, New York.

Featherstone, E., Trimble, M.R., Dolan, R.J., Nagai, Y. and Critchley, H.D. (2004) 'Activity in ventromedial prefrontal cortex covaries with sympathetic skin conductance level: a physiological account of a 'default mode' of brain function', NeuroImage, Vol. 22, No. 1, pp.243-251.

Friesen, W.V., Elkman, P. and Levenson, R.W. (1983) 'Autonomic nervous system activity distinguishes among emotions’, Science, Vol. 221, No. 4616, pp.1208-1210.

Hecht, D. (2010) 'Depression and the hyperactive right-hemisphere', Neuroscience Research, Vol. 68, No. 2, pp.77-87.

Just, M.A., Cherkassky, V.L., Aryal, S. and Mitchell, T.M. (2010) 'A neurosemantic theory of concrete noun representation based on the underlying brain codes', PLOS ONE, Vol. 5, No. 1, p.e8622, doi:10.1371/journal.pone.0008622. 
Ketter, T.A., Parekh, P.I., Horwitz, B. and George, M.S. (1995) 'Brain activity during transient sadness and happiness in healthy women', The American Journal of Psychiatry, March, Vol. 152, No. 3, pp.341-351.

Lang, P.J. and Bradley, M.M. (2000) 'Affective reactions to acoustic stimuli', Psychophisiology, Vol. 37, No. 2, pp.204-215.

Losch, M.E., Kim, H.S., Cacioppo, J.T. and Petty, R.E. (1986) 'Electromyographic activity over facial muscle regions can differentiate the valence and intensity of affective reactions', Journal of Personality and Social Psychology, Vol. 50, No. 2, pp.260-268.

Meyer, N. and Kotter, R. (1992) 'The limbic system: a review of its empirical foundation', Behavioural Brain Research, Vol. 52, No. 2, pp.105-127.

Nagai, Y., O’Doherty, J., Mathiasc, C.J., Dolan, R.J., Critchley, H.D. and Rotshtein, P. (2005) 'Activity in the human brain predicting differential heart rate responses to emotional facial expressions', NeuroImage, Vol. 24, No. 3, pp.751-762.

Ohman, A. (2008) 'Fear and anxiety. Overlaps and dissociations', in M. Lewis, J.M. Haviland-Jones and L. Feldman Barrett (Eds.): Handbook of Emotions, pp.709-729, The Guilford Press, New York.

Panksepp, J. (2008) 'The affective brain and core consciousness', in M. Lewis, J.M. Haviland-Jones and L. Feldman Barrett (Eds.): Handbook of Emotions, pp.47-68, The Guilford Press, New York.

Phelps, E.A. and Olsson, A. (2007) 'Social learning of fear', Nature Neuroscience, Vol. 10, No. 9, pp.1095-1102.

Phelps, E.A. and Ledoux, J.E. (2008) 'Emotional networks in the brain', in M. Lewis, J.M. Haviland-Jones and L. Feldman Barrett (Eds.): Handbook of Emotions, pp.159-179, The Guilford Press, New York.

Poehlmann, K.M., Ito, T.A., Cacioppo, J.T., Larsen, J.T. and Berntson, G.G. (2008) 'The psychophysiology of emotion', in M. Lewis, J.M. Haviland-Jones and L. Feldman Barrett (Eds.): Handbook of Emotions, pp.180-195, The Guilford Press, New York.

Salt, P., Mandel, M.R., Klerman, G.R., Schwartz, G.E. and Fair, P.L. (1976) 'Facial muscle patterning to affective imagery in depressed and nondepressed subjects', Science, Vol. 192, No. 4238, pp.489-491.

Tulceanu, V. (2012) 'Comprehensive brainwave authentication using emotional stimuli', in Proceedings of the 20th European Signal Processing Conference, EUSIPCO, Bucharest, Romania, August 27-31, pp.1772-1776. 